\title{
Interval-fuzzy municipal-scale energy model for identification of optimal strategies for energy management - A case study of Tianjin, China
}

\author{
C. Chen ${ }^{\text {a, b}}$, Y.P. Li ${ }^{\text {b, c, }}{ }^{*}$, G.H. Huang ${ }^{\text {b, c }}$ \\ a Institute of Geographic Sciences and Natural Resources Research, China Academy of Sciences, Beijing 100101, China \\ ${ }^{\mathrm{b}}$ MOE Key Laboratory of Regional Energy Systems Optimization, Sino-Canada Resources and Environmental Research Academy, North China Electric Power \\ University, Beijing 102206, China \\ c Environmental Systems Engineering Program, Faculty of Engineering and Applied Science, University of Regina, Regina, Sask. S4S 0A2, Canada
}

\section{A R T I C L E I N F O}

\section{Article history:}

Received 14 November 2013

Received in revised form

6 September 2015

Accepted 19 September 2015

Available online 30 September 2015

\section{Keywords:}

Energy system

Fuzzy programming

Modeling

Planning

Municipal-scale

Renewable energy

\begin{abstract}
A B S T R A C T
An interval-fuzzy municipal-scale energy model (IF-MEM) is developed for energy systems planning. IFMEM can effectively tackle uncertainties presented in terms of fuzzy sets and discrete intervals. IF-MEM is applied to a real case of energy systems planning in the City of Tianjin, which is the economic and industrial center of northern China. IF-MEM allows in-depth analyses for tradeoffs among economic objective, satisfaction degree, and constraint-violation risk. The results indicate that reasonable solutions have been generated. The results suggest that: (i) coal would be the dominant sources in city's energy systems due to the increasing energy demand; however, its consumption ratio would decrease over the planning horizon due to requirements of environment protection and sustainable development; (ii) clean (e.g., natural gas, liquefied petroleum gas) and renewable energies (e.g., wind power, solar power) would be vigorously encouraged during the planning periods; (iii) coal-fired technology (i.e., coal-fired power and heat) would be the major contributor for the city's atmosphere pollution; (iv) the pollutant emissions would be decreased over the planning horizon due to the restriction of fossil fuels and the development of renewable energy. Promoting the utilization of renewable energy sources is crucial for supporting pollutant emission reduction and solving energy shortage crisis.
\end{abstract}

(C) 2015 Published by Elsevier Ltd.

\section{Introduction}

Energy demand and supply have shown a soaring increase trend because of rapid economic development, speedy population growth, and human-life quality improvement. According to the recent IEA report, the global energy demand is growing at a rate of about $1.6 \%$ per year, and is expected to reach about $700 \times 10^{18} \mathrm{~J} /$ Year by 2030 , with more than $83 \%$ of worldwide primary energy production still coming from combustion of fossil fuels [1,2]. For example, in China, the total energy consumption reached 3.48 billion ton of coal equivalent in 2011, with an increment of $7 \%$ from 2010; the consumption increments for coal, oil, natural gas, and electricity are $9.7 \%, 2.7 \%, 12 \%$ and $11.7 \%$, respectively [3]. By 2010 , China is the largest energy consumption country throughout the

\footnotetext{
* Corresponding author.

E-mail addresses: yongping.li@iseis.org (Y.P. Li), gordon.huang@uregina.ca (G.H. Huang).
}

world, which accounts for $20.3 \%$ of the world and its coal-fired power occupies more than $75 \%$ of the total electricity generation [4]. The exploration and utilization of energy resources bring serious energy depletion and environmental problems [5]. Such situations have forced decision makers to contemplated and proposed comprehensive and ambition plans for managing and planning energy systems. However, such planning efforts are complicated with a variety of processes that should be considered by decision makers, including energy production, supply, import/ export, conversion, transmission and consumption [6]. It is necessary to develop effective optimization methods for supporting energy system planning under such complexities.

Previously, a number of optimization methods were effective in providing optimal decision alternatives for energy systems planning and management [7-22]. For example, the market allocation model (MARKAL) was developed as a large-scale, technology-oriented energy-activity analysis modeling system. Based on MARKAL, sectors of energy production, conversion, processing, transmission 
and consumption can be incorporated within a general framework to help formulate cost-effective energy-related plans [9-12,23,24]. Brookhaven energy system optimization model (BESOM) was used to identify optimal mixing patterns of energy sources, technologies and investments within an energy management system under the minimized economic cost $[8,25]$. Energy flow optimization model (EFOM) was established as an engineering-oriented bottom-up model for national energy management systems planning and widely used in many European countries [7,8,26-28]. Colony optimization electricity energy estimation model (ACOEEM) was established to present Turkey's electricity energy generation and demand situation, which used population, gross domestic product, import and export as indicators [13]. In general, the above models were based on techniques of mixed-integer linear programming as well as linear and nonlinear programming, which were emphasized on the planning of either individual energy sectors or general energy systems under deterministic conditions [29,30].

In fact, many processes in energy systems (e.g., energy production, conversion, transmission and supply) are often complicated by the interactions of many factors (e.g., environmental, economic, social and political) and relationships among different energy processes; any changes in one sector could lead to a series of consequences, resulting in variations in system costs and environmental impacts [31,32]. For example, if local availabilities of renewable energy resources are insufficient to meet end-user energy demand, a certain degree of energy-supply risk may exist. This could result in shifts of the existing technologies/resources over a long term and induce additional economic cost. These complexities could lead to various uncertainties existing in energy systems planning and management activities. For example, economic data (i.e. cost and benefit) can hardly be acquired as deterministic values but easily expressed as intervals; the interval values can be used for describing uncertain information of planning issues which fluctuates within a range without distribution information. The other system's vagueness and ambiguity parameters could be expressed as fuzzy sets; the fuzzy sets can be used for reflecting uncertain information which can be expressed as intervals subject to known possibilistic distributions [33]. In planning such energy systems, independent consideration of one or several sectors or ignorance the various uncertainties would be unable to completely reflect the overall system characteristics, which would affect the normal operation of energy systems as well as lead various energy systemfailure risks (e.g., resource-availability risk, energy-supply risk).

This study aims to develop an interval-fuzzy municipal-scale energy model (IF-MEM) to support energy systems planning and environmental management under uncertainty. The IF-MEM incorporates techniques of interval-parameter programming (IPP) and fuzzy flexible programming (FP) within a mixed-integer linear programming (MILP) framework for dealing with uncertainties expressed as intervals and fuzzy sets. Then, a real case of planning energy systems of Tianjin will then be provided for demonstrating the applicability of the developed method. The detailed tasks entail: (i) dealing with the uncertainties expressed as fuzzy sets and intervals in the objective functions and constraints, (ii) generating solutions of energy resource allocation, electricity generation, heat generation, capacity expansion, and emission abatement with a minimized system cost, (iii) evaluating the situation of energy consumption of Tianjin's traffic system, and (iv) coordinating the conflict interactions among economic cost, system reliability, pollutant mitigation, and energy-supply security.

\section{Methodology}

A decision in a fuzzy environment can be defined as the intersection of membership functions corresponding to fuzzy objective and constraints [34-36]. Fuzzy programming (FP) can deal with vagueness and ambiguity based on fuzzy set theory, where uncertainties are handled in a direct way without a large number of realizations [36]. Given a fuzzy goal $(G)$ and a fuzzy constraint $(C)$ in a space of decision alternatives $(X)$, a fuzzy decision set $(D)$ can then be formed in the intersection of $G$ and $C$. In a symbolic form, we have $D \cap C$, and correspondingly:

$\mu_{D}=\operatorname{Min}\left\{\mu_{G}, \mu_{C}\right\}$

where $\mu_{D}, \mu_{G}$ and $\mu_{C}$ denote membership functions of fuzzy decision $D$, fuzzy goal $G$, and fuzzy constraint $C$, respectively $[35,36]$.

Assume that we have $\mathrm{n}$ goals $\left(G_{1}, G_{2}, \ldots, G_{n}\right)$ and $\mathrm{m}$ constraints $\left(C_{1}, C_{2}, \ldots, C_{m}\right)$. The resulting decision will then be an intersection of the given goals and constraints as follows:

$D=G_{1} \cap G_{2} \cap \ldots \cap G_{n} \cap C_{1} \cap C_{2} \cap \ldots \cap C_{m}$

and correspondingly,

$\mu_{D}=\operatorname{Min}\left\{\mu_{G_{1}} \cap \mu_{G_{2}} \cap \ldots \cap \mu_{G_{n}} \cap \mu_{C_{1}} \cap \mu_{C_{2}} \cap \ldots \cap \mu_{C_{m}}\right\}$

Let $\mu_{C_{i}}(X)$ be membership functions of constraints $C_{i}(i=1,2, \ldots$, $\mathrm{m})$, and $\mu_{G_{i}}(X)$ be those of goals $G_{j}(j=1,2, \ldots, \mathrm{n})$. A decision can then be defined by the following membership function $[35,36]$ :

$\mu_{D}(X)=\mu_{C_{i}}(X)^{*} \mu_{G_{j}}(X)$

where “*” denotes an appropriate and possibly context-dependent "aggregator"; $X$ represents a set of fuzzy decision variables.

FP methods can effectively reflect uncertainties expressed as fuzzy sets; however, they are infeasible to treat uncertainties presented as interval values without knowing their membership functions. Interval-parameter programming (IPP) is effective for handling uncertainties in objective function and constraints, since interval numbers are acceptable as its uncertain inputs [37,38]. Therefore, one potential approach for accounting for fuzzy and interval uncertainties is to combine the IPP with FP; this leads to an interval-fuzzy linear programming (IFLP) model as follows:

$\operatorname{Min} f^{ \pm} \equiv C^{ \pm} X^{ \pm}$

subject to:

$A^{ \pm} X^{ \pm} \lesseqgtr B^{ \pm}$

$X^{ \pm} \geq 0$

where $A^{ \pm} \in\left\{R^{ \pm}\right\}^{m \times n}, B^{ \pm} \in\left\{R^{ \pm}\right\}^{m \times 1}, C^{ \pm} \in\left\{R^{ \pm}\right\}^{1 \times n}, X^{ \pm} \in\left\{R^{ \pm}\right\}^{n \times 1}$, and $\left\{R^{ \pm}\right\}$denote a set of interval numbers, and $m$ and $n$ are real numbers ( $m \geq 1$ and $n \geq 1$ ); $X^{ \pm}$represent a set of decision variables; the "-" and "+" superscripts denote the lower and upper bounds of interval parameters/variables, respectively; symbols " $\equiv$ " and “ $\lesssim$ " represent fuzzy equality and inequality, respectively.

The $\mu_{i}\left(X^{ \pm}\right)$can be interpreted as degree to which $X^{ \pm}$satisfies fuzzy inequality in the objective and constraints [35,39,40]. A desired decision is thus the one with the highest $\mu_{D}\left(X^{ \pm}\right)$value:

$\operatorname{Max} \mu_{D}\left(X^{ \pm}\right)=\operatorname{Max} \operatorname{Min}\left[\mu_{i}\left(X^{ \pm}\right)\right], X^{ \pm} \geq 0$

where $\mu_{i}\left(X^{ \pm}\right)$should be "0" if the objective and constraints are violated, and " 1 " if they are satisfied. Model (5) can be converted into an ordinary linear programming one by introducing a new variable of $\lambda=\mu_{D}\left(X^{ \pm}\right)$, which corresponds to the membership function of the fuzzy decision [36]. Specifically, the flexibility in the 
constraints and fuzziness in the objective (which are represented by fuzzy sets and denoted as "fuzzy constraints" and "fuzzy goal", respectively) can be expressed as membership grades $(\lambda)$ corresponding to degrees of overall satisfaction for the constraints and objective. Thus, model (5) can be converted into:

$\operatorname{Max} \lambda^{ \pm}$

subject to:

$C^{ \pm} X^{ \pm} \leq f^{+}-\lambda^{ \pm}\left(f^{+}-f^{-}\right)$

$A^{ \pm} X^{ \pm} \leq B^{+}-\lambda^{ \pm}\left(B^{+}-B^{-}\right)$

$X^{ \pm} \geq 0$

$0 \leq \lambda^{ \pm} \leq 1$

where $f^{-}$and $f^{+}$are the lower and upper bounds of the objective's aspiration level, respectively; $\lambda^{ \pm}$is the control variable corresponding to the degree (membership grade) of satisfaction for the fuzzy decision. An interactive two-step algorithm is developed to solve the above problem through analyzing the detailed interrelationships between the parameters and the variables and between the objective function and the constraints [36,41]. The submodel for $\lambda^{+}$corresponding to $f^{-}$can be formulated in the first step when the system objective is to be minimized; the other submodel for $\lambda^{-}$can then be formulated based on the solution of the first submodel. The first submodel is (assume that $b_{i}^{ \pm}>0$ and $f^{ \pm}$ $>0)$ :

\section{$\operatorname{Max} \lambda^{+}$}

subject to:

$\sum_{j=1}^{k 1} c_{j}^{-} x_{j}^{-}+\sum_{j=k_{1}+1}^{h} c_{j}^{-} x_{j}^{+} \leq f^{+}-\lambda^{+}\left(f^{+}-f^{-}\right)$

$$
\begin{gathered}
\sum_{j=1}^{k_{1}}\left|a_{i j}\right|^{+} \operatorname{Sign}\left(a_{i j}^{+}\right) x_{j}^{-}+\sum_{j=1}^{k_{1}}\left|a_{i j}\right|^{-} \operatorname{Sign}\left(a_{i j}^{-}\right) x_{j}^{+} \\
\leq b_{i}^{-}+\left(1-\lambda^{+}\right)\left(b_{i}^{+}-b_{i}^{-}\right), \quad \forall i
\end{gathered}
$$

$x_{j}^{ \pm} \geq 0, \quad \forall j$

$0 \leq \lambda^{+} \leq 1$

$x_{j}^{ \pm} \geq 0, \quad \forall j$

where $x_{j}^{-}\left(j=1,2, \ldots, k_{1}\right)$ are decision variables with positive coefficients in the objective function, and $x_{j}^{-}\left(j=k_{1}+1, k_{1}+2, \ldots, n\right)$ with negative coefficients. Solutions of $x_{j}^{-}\left(j=1,2, \ldots, k_{1}\right)$, $x_{j}^{+}\left(j=k_{1}+1, k_{1}+2, \ldots, n\right)$ and $\lambda^{+}$can be obtained by solving submodel (8). Based on the above solutions, the second submodel corresponding to $\lambda^{-}$can be formulated as follows:

$\operatorname{Max} \lambda^{-}$

subject to:

$$
\sum_{j=1}^{k 1} c_{j}^{+} x_{j}^{+}+\sum_{j=k_{1}+1}^{h} c_{j}^{+} x_{j}^{-} \leq f^{+}-\lambda^{-}\left(f^{+}-f^{-}\right)
$$

$\sum_{j=1}^{k_{1}}\left|a_{i j}\right|^{-} \operatorname{Sign}\left(a_{i j}^{-}\right) x_{j}^{+}+\sum_{j=1}^{k_{1}}\left|a_{i j}\right|^{+} \operatorname{Sign}\left(a_{i j}^{+}\right) x_{j}^{-}$

$$
\leq b_{i}^{-}+\left(1-\lambda^{-}\right)\left(b_{i}^{+}-b_{i}^{-}\right), \quad \forall i
$$

$x_{j}^{ \pm} \geq 0, \quad \forall j$

$0 \leq \lambda^{+} \leq 1$

$x_{j}^{-} \leq x_{j}^{+}, \quad \forall j=1,2, \ldots, k_{1}$

$x_{j}^{-} \geq x_{j}^{+} \geq 0, \quad \forall j=k_{1}+1, k_{1}+2, \ldots, n$

Solutions of $x_{j}^{+}\left(j=1,2, \ldots, k_{1}\right)$ and $x_{j}^{-}\left(j=k_{1}+1, k_{1}+2, \ldots, n\right)$ and $\lambda^{-}$can be obtained through solving submodel (9). Combining solutions of submodels (8) and (9), solutions for the IFLP model can be obtained as follows:

$$
\begin{array}{ll}
x_{j o p t}^{ \pm}=\left[x_{j}^{-}, x_{j}^{+}\right], & \forall j \\
\lambda_{j o p t}^{ \pm}=\left[\lambda_{j}^{-}, \lambda_{j}^{+}\right], & \forall j \\
f_{j o p t}^{ \pm}=\left[f^{-}, f^{ \pm}\right], & \forall j
\end{array}
$$

\section{Study system}

Tianjin, as one of the largest municipalities with an area of $11,946 \mathrm{~km}^{2}$, is the economic and industrial center of northern China. The city's population is approximately 9.8 million in 2009, with a growth rate of $2.23 \%$ per year. As shown in Fig. 1,15 zones and 3 counties are considered in the study region, including Jixian, Baodi, Wuqing, Ninghe, Beichen, Hanggu, Xiqing, dongLi, Tanggu, Jingnan, Jinghai, Dagang and urban area (e.g., Hongqiao, Nankai, Hexi, Hedong, Hebei and Heping zones). Tianjin's economy has experiencing a rapid development in the past decades, which mainly depends on industry. According to Tianjin Statistical Bureau, the gross domestic product (GDP) of Tianjin reached to RMB $¥$ 752.18 billion in 2009 , with a growth rate of $16 \%$ per year. The gross output value of industry is RMB $¥ 362.21$ billion, accounting for $48 \%$ of the total GDP [42]. With the increasing development of economy and society, the total amount of energy demand has a rapid growth.

Along with increasing energy consumption, the city faces a growing pressure to maintain the balance between energy supply and demand [30]. According to the Tianjin Statistical Bureau, the total amount of energy consumption was 45.26 million ton of coal equivalent in 2005, and increased to 75.98 million ton of coal equivalent in 2011 , with a growth rate of $40.43 \%$. The city's coal supply depends on purchasing coal from other regions (i.e., Shanxi, Inner-Mongolia and Hebei provinces) because there is no local coal mine. The consumption of coal reached to 52.62 million ton in 2011, which accounted for $69.24 \%$ of the total energy consumption [43]. Crude oil and natural gas are the mainly energy products of Tianjin, which are produced from four oil deposits (i.e., Dagang, Changqing, Bohai and Huabei oil deposits). The total energy production is 48.33 


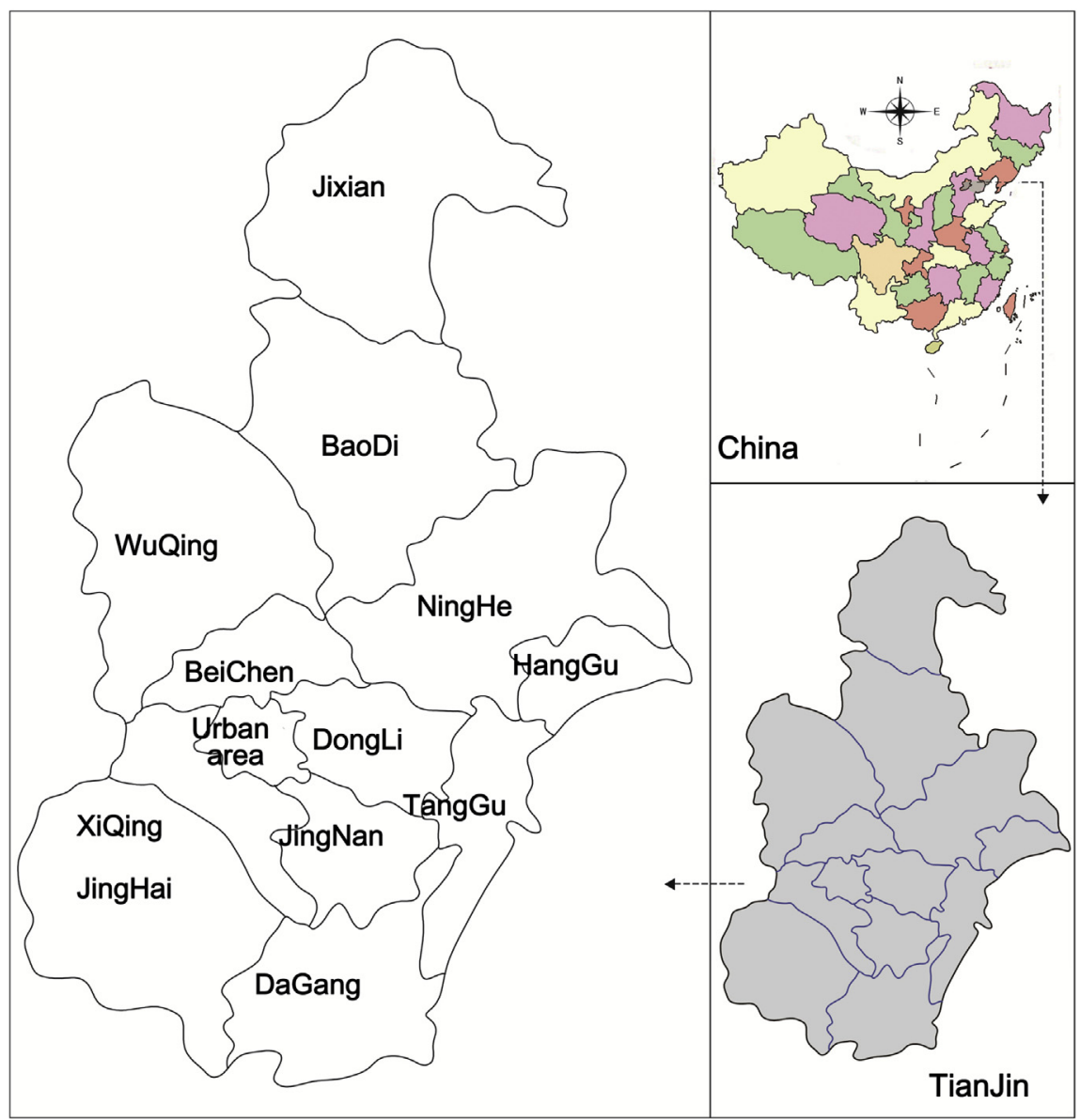

Fig. 1. Geographical position and districts of Tianjin.

million ton of coal equivalent, and the crude oil and natural gas account for $94.39 \%$ and $5.10 \%$, respectively [43]. Besides, the city is also responsible for supplying crude oil to other regions such as Hebei provinces and Beijing municipality. Currently, approximately $20 \%$ of natural gas supply depends on "West-to-East Gas transport" project because the local gas production cannot meet the city's demand. The city's total amount of electricity consumption increased from 44.5 billion KWh in 2005 to 72.7 billion KWh in 2011, where $14.03 \%$ of electricity should be imported from other regions to meet its electricity demand [43]. Summarily, the city's energy end produce and consumption structures has been improved in the recent years; the proportion of coal is gradually decreasing, however, the coal still plays a dominate role in Tianjin's energy supply. Such a situation leads to the fossil fuel reserves continuously shrinking and serious atmospheric environment issues. Therefore, it is necessary to propose comprehensive and ambition plans to balance increasing energy demands, reduce fossil fuel consumption, and mandate requirement for mitigating pollutant and greenhouse gas emissions.

Energy sector is a major contributor of pollutant emissions in the city. A large number of fossil fuels (such as coal, crude oil, and natural gas) bring about serious atmospheric environment issues. The following characteristics can be observed on air pollution in Tianjin: sulfur dioxide $\left(\mathrm{SO}_{2}\right)$, nitric oxide $\left(\mathrm{NO}_{\mathrm{X}}\right)$ and inhalable particle $\left(\mathrm{PM}_{10}\right)$ mainly come from burning fossil fuels and other energy related activities. For example, the $\mathrm{SO}_{2}$ emissions from burning fossil fuels were $221.9 \times 10^{3}$ ton, which accounts for $96 \%$ of total $\mathrm{SO}_{2}$ emissions [43]. The $\mathrm{NO}_{\mathrm{X}}$ and $\mathrm{CO}$ emissions from fossil fuels account for about $67 \%$ and $70 \%$, respectively. Fig. 2 presents the annual average concentration of mainly pollutants from 2005 to 2011. The $\mathrm{SO}_{2}$ and $\mathrm{PM}_{10}$ average concentration are obviously higher that the standard regulated which have negative effects on the human health and hinder the sustainable development of the city. Therefore, it is necessary to adopt a series of measures to in order to reduce pollutant emissions. For example, promoting the utilization of renewable energy resources, such that gas-fired power, wind power, and solar power; building new coal-fired power plant far from central urban area and new costal region; installing flue gas desulfurization, denitration and dust extraction systems for coalfired power plants.

The city's transportation system is mainly composed of bus, taxi, private cars, railway and light rail. By 2010 , the number of automotive vehicles reached 2.06 million (with $54.37 \%$ of private car). Gasoline and diesel are the main fuels for automotive vehicles. According the Chinese energy statistical yearbook [44], Tianjin's consumption amount of gasoline and diesel had reached to $650.1 \times 10^{3}$ and $1293.0 \times 10^{3}$ ton until 2012 , which with a rapid growth rate of $5.32 \%$ and $5.15 \%$ per year, respectively. The fast growth of motor vehicles and transportation fuels inevitably lead to severe air pollution [45]. The sharply increasing automotive vehicles and energy consumption of traffic systems have resulted huge amount of vehicle exhausts. $\mathrm{CO}, \mathrm{NO}_{\mathrm{X}}$ and $\mathrm{HC}$ are major pollutants of vehicle exhausts. According to Chinese environment statistical yearbook (2013) [46], the $\mathrm{NO}_{\mathrm{x}}$ emissions from the traffic system had reached to 557 million tons, which accounted for about $20 \%$ of the total emissions. The huge amount of pollutant emissions have 


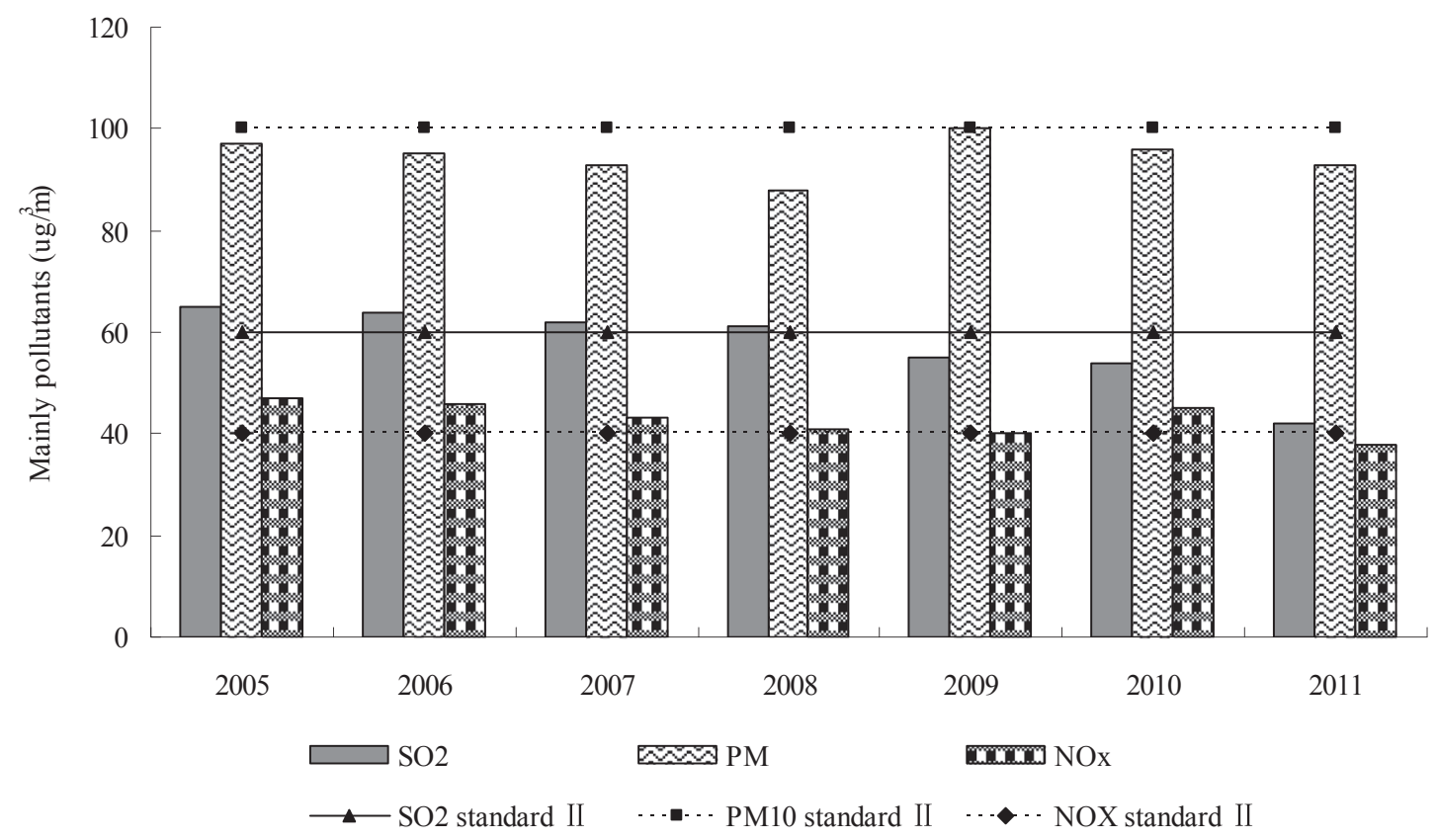

Fig. 2. Annual average concentration of mainly pollutants in Tianjin $\left(\mu \mathrm{g} / \mathrm{m}^{3}\right)$.

severely influence on the human body health. In order to control the pollutant emissions from the traffic system, it is necessary to enhance public transport and low carbon transport (including bus, taxi and railways) to meet the increasing transportation demand.

In the study system, multiple energy resources (such as coal, crude oil, natural gas, diesel, gasoline and kerosene) are conversed into terminal energy carries (such as electricity and heat), which are employed for satisfying the corresponding demands on various energy productions from multiple end-users (i.e., agriculture, industrial, commercial, transportation and residential sectors) [47]. Fig. 3 shows interactive relationships between different processes in energy systems, including energy production, import/export, storage, conversion, transmission, air pollutants mitigation and relevant activities. Many complex processes in the city's energy systems that should be considered by decision makers. Moreover, many system parameters (such as resource availability, the price of energy, electricity demands, production efficiency) are uncertain, which are presented in terms of interval values or fuzzy sets. These uncertainties can multiply the complexities of energy systems, which could affect the related optimization processes and the generated decision schemes [30]. Therefore, the relevant decisions must be made under various uncertainties in order to select the most appropriate power conversion technology and type of fuel to meet the electricity demand and the most suitable pollution mitigation technology to satisfy the environmental constraints, according to the availability, economic, environmental and technological characteristics of different fuels and technologies $[47,48]$. The study time horizon is 15years (from 2014 to 2028), which is further divided into three planning periods with each period being five years (i.e., period 1: 2014-2018; period 2: 2019-2023; period 3: 2024-2028). The representative benefit/cost and technical data (as shown in Tables 1-4) were investigated based on a number of governmental reports and many related references $[4,17,30,31,42-45,49,50]$. Table 1 shows the energy demands over the planning horizon, where, energy demands increase gradually with the population growth and economic development. The renewable energy resources have been strongly encouraged during the planning horizon, due to the practicing of energy policies made by the local government. Table 2 lists the supply costs for energy sources over the planning horizon. The prices of energy sources are expressed as intervals, which within their lower and upper bounds. Table 3 provides operating and expansion costs of electric and thermal power plants. When the energy supply cannot sufficiently meet the end-users' demands, the system would face the risk of energy shortage. Decision makers have to invest more funds into energy imports at raised prices to satisfy the increasing energy demand. $\mathrm{SO}_{2}, \mathrm{NOx}$, and $\mathrm{PM}_{10}$ are the main pollutants emitted from the energy system. Different removal technologies are used for controlling these pollutants. The operating cost for pollution control technology is listed in Table 4.

\section{IF-MEM modeling formulation}

Based on the IFLP method developed in Section 2, an intervalfuzzy municipal-scale energy model (IF-MEM) is formulated for planning energy systems of Tianjin. The IF-MEM can be effective for: (a) assigning energy resources to different conversion technologies with a minimized system cost, (b) generating an optimized electricity and heating production scheme with economic and environmental consideration, (c) dealing with the uncertainties expressed as fuzzy sets and interval in the objective functions and constraints, and (d) evaluating the environment impact and energy consumption amount from traffic system of Tianjin.

\subsection{Objective function}

The objective of IF-MEM is to maximize $\lambda^{ \pm}$, where $\lambda^{ \pm}$should be satisfied Formula (11-1).

$$
\begin{aligned}
& (1)-(2)+(3)+(4)+(5)+(6)+(7)+(8)+(9)+(10) \\
& \leq f_{o p t}^{+}-\lambda^{ \pm}\left(f_{o p t}^{+}-f_{o p t}^{-}\right)
\end{aligned}
$$




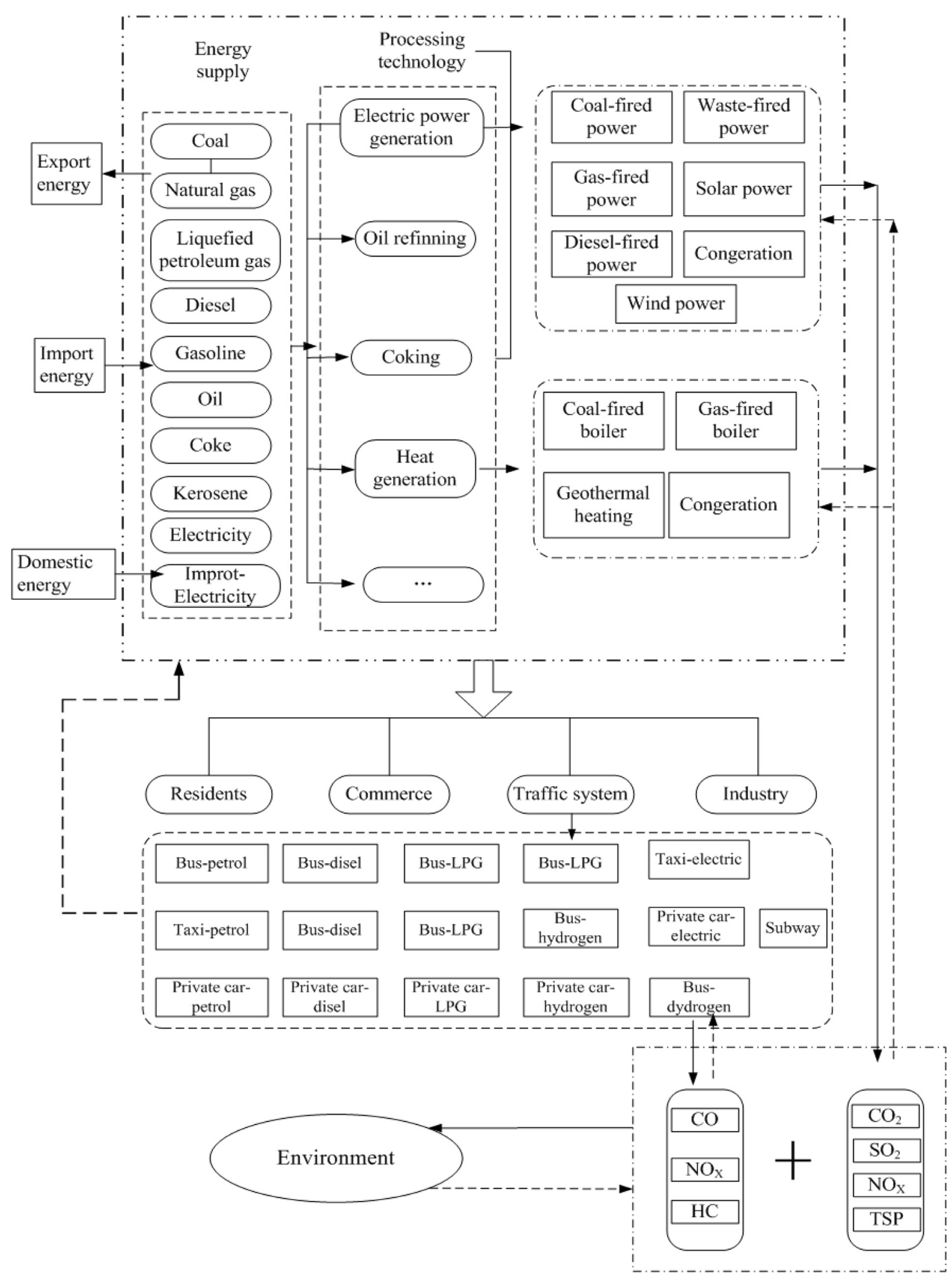

Fig. 3. Diagram of energy management system in Tianjin. 
Table 1

Energy demand.

\begin{tabular}{|c|c|c|c|}
\hline \multirow[t]{2}{*}{ Energy resource } & \multicolumn{3}{|l|}{ Planning period } \\
\hline & Period 1 & Period 2 & Period 3 \\
\hline Improt coal ( $10^{6}$ ton $)$ & {$[200.6,320.6]$} & {$[228.9,348.9]$} & {$[234.7,354.7]$} \\
\hline Natural gas $\left(10^{9} \mathrm{~m}^{3}\right)$ & {$[8.4,15.5]$} & {$[16.0,23.0]$} & {$[30.9,37.1]$} \\
\hline Liquefied petroleum gas ( $10^{3}$ ton) & {$[2060,3260]$} & {$[3070,4370]$} & {$[6960,8260]$} \\
\hline Diesel $\left(10^{6}\right.$ ton $)$ & {$[23.9,24.1]$} & {$[28.4,35.4]$} & {$[44.3,45.3]$} \\
\hline Gasoline $\left(10^{6}\right.$ ton $)$ & {$[7.9,15.9]$} & {$[10.3,18.2]$} & {$[15.1,30.1]$} \\
\hline Fuel oil ( $10^{3}$ ton $)$ & {$[5780,6980]$} & {$[5910,7310]$} & {$[6690,8890]$} \\
\hline Oil $\left(10^{6}\right.$ ton $)$ & {$[43.4,55.4]$} & {$[60.7,72.7]$} & {$[76.4,87.4]$} \\
\hline Coke $\left(10^{6}\right.$ ton $)$ & {$[38.0,49.0]$} & {$[71.4,82.4]$} & {$[111.1,169.1]$} \\
\hline Kerosene $\left(10^{3}\right.$ ton $)$ & {$[950,3110]$} & {$[1640,4840]$} & {$[2520,5820]$} \\
\hline Electricity $\left(10^{6}\right.$ ton $)$ & {$[26.9,38.9]$} & {$[38.9,49.9]$} & {$[49.9,62.9]$} \\
\hline
\end{tabular}

Table 2

Energy cost.

\begin{tabular}{llll}
\hline Energy purchase cost (RMB¥/ton) & \multicolumn{3}{l}{ Planning period } \\
\cline { 2 - 4 } & Period 1 & Period 2 & Period 3 \\
\hline Import coal & {$[545,645]$} & {$[650,750]$} & {$[720,820]$} \\
Natural gas & {$[8500,9000]$} & {$[7500,8000]$} & {$[6500,7000]$} \\
Liquefied petroleum gas & {$[4905,5505]$} & {$[5190,5690]$} & {$[5362,5862]$} \\
Diesel & {$[6508,6808]$} & {$[6854,7254]$} & {$[6925,7525]$} \\
Gasoline & {$[6930,7230]$} & {$[7321,7621]$} & {$[7542,7842]$} \\
Fuel oil & {$[5954,6254]$} & {$[6325,6625]$} & {$[6514,6814]$} \\
Oil & {$[5604,5904]$} & {$[6014,6414]$} & {$[6234,6734]$} \\
Coke & {$[1671,1971]$} & {$[2011,2411]$} & {$[2214,2714]$} \\
Kerosene & {$[7730,8330]$} & {$[8125,8425]$} & {$[8345,8745]$} \\
Import-electricity & {$[6300,6500]$} & {$[6500,6600]$} & {$[6600,6800]$} \\
Energy selling cost & & & \\
Import coal & {$[545,645]$} & {$[650,750]$} & {$[720,820]$} \\
Natural gas & {$[8500,9000]$} & {$[7500,8000]$} & {$[6500,7000]$} \\
Liquefied petroleum gas & {$[4905,5505]$} & {$[5190,5690]$} & {$[5362,5862]$} \\
Diesel & {$[6508,6808]$} & {$[6854,7254]$} & {$[6925,7525]$} \\
\hline
\end{tabular}

Table 3

Operating and expansion of electric and thermal power plant.

\begin{tabular}{|c|c|c|c|}
\hline \multirow[t]{2}{*}{ Energy purchase cost } & \multicolumn{3}{|c|}{ Planning period } \\
\hline & Period 1 & Period 2 & Period 3 \\
\hline \multicolumn{4}{|c|}{ Operation cost of electric power plant (RMB $\left.¥ 10^{9} / 10^{12} \mathrm{KWh}\right)$} \\
\hline Coal-fired power & {$[150,160]$} & {$[180,190]$} & {$[200,210]$} \\
\hline Gas-fired power & {$[80,90]$} & {$[90,100]$} & {$[100,110]$} \\
\hline Oil-fired power & {$[90,100]$} & {$[100,110]$} & {$[110,120]$} \\
\hline Wind & {$[450,460]$} & {$[400,425]$} & {$[350,370]$} \\
\hline Waste-fired & {$[250,270]$} & {$[220,240]$} & {$[200,220]$} \\
\hline Solar power & {$[300,330]$} & {$[300,320]$} & {$[280,300]$} \\
\hline Cogeneration & {$[100,110]$} & {$[130,140]$} & {$[150,160]$} \\
\hline \multicolumn{4}{|c|}{ Expansion cost of electric power plant (RMB $¥ 10^{3} / \mathrm{KW}$ ) } \\
\hline Coal-fired power & {$[3.4,3.6]$} & {$[3.5,3.7]$} & {$[3.8,4.0]$} \\
\hline Gas-fired power & {$[3.5,3.6]$} & {$[3.7,3.8]$} & {$[3.8,3.9]$} \\
\hline Oil-fired power & {$[3.4,3.6]$} & {$[3.6,3.8]$} & {$[3.7,3.9]$} \\
\hline Wind & {$[9.0,1.1]$} & {$[8.0,9.0]$} & {$[7.0,8.0]$} \\
\hline Waste-fired & {$[13.6,13.7]$} & {$[13.5,13.6]$} & {$[13.4,13.5]$} \\
\hline Solar power & {$[29.4,31.4]$} & {$[27.4,29.4]$} & {$[22.9,26.9]$} \\
\hline Cogeneration & {$[5.0,6.0]$} & {$[5.5,6.5]$} & {$[5.5,7.0]$} \\
\hline \multicolumn{4}{|c|}{ Operation cost of thermal power plant $\left(\mathrm{RMB} ¥ / \mathrm{m}^{\mathbf{3}}\right)$} \\
\hline Coal-fired boiler & {$[16.5,18.5]$} & {$[17.0,21.0]$} & {$[18.0,23.0]$} \\
\hline Gas-fired boiler & {$[29,30]$} & {$[30,33]$} & {$[31,35]$} \\
\hline Geothermal heating & {$[55,57]$} & {$[52,59]$} & {$[50,62]$} \\
\hline Cogeneration & {$[25,28]$} & {$[26,29]$} & {$[27,31]$} \\
\hline \multicolumn{4}{|c|}{ Expansion cost of thermal power plant (RMB $\left.¥ 10^{3} / \mathrm{MW}\right)$} \\
\hline Coal-fired boiler & {$[330,340]$} & {$[340,360]$} & {$[360,370]$} \\
\hline Gas-fired boiler & {$[580,590]$} & {$[600,620]$} & {$[620,615]$} \\
\hline Geothermal heating & {$[2000,2100]$} & {$[2000,2200]$} & {$[1000,1200]$} \\
\hline Cogeneration & {$[1000,1300]$} & {$[950,1000]$} & {$[900,950]$} \\
\hline
\end{tabular}

Table 4

Operating cost of pollution control technology (RMB $¥ /$ ton).

\begin{tabular}{llll}
\hline Pollution treatment cost & \multicolumn{3}{l}{ Planning period } \\
\cline { 2 - 4 } & Period 1 & Period 2 & Period 3 \\
\hline $\mathrm{SO}_{2}$ & {$[55,65]$} & {$[54,64]$} & {$[53,61]$} \\
$\mathrm{NOx}$ & {$[50,52]$} & {$[49,51]$} & {$[48,50]$} \\
$\mathrm{PM}_{10}$ & {$[185,195]$} & {$[182,192]$} & {$[180,185]$} \\
\hline
\end{tabular}

(1) Cost for primary energy supply:

$E S C^{ \pm}=\sum_{i=1}^{9} \sum_{t=1}^{3} P D_{i t}^{ \pm} \cdot Z_{i t}^{ \pm}$

where $i$ is the type of energy source, $i=1,2, \ldots, 10$ (where $i=1$ for brought in coal, 2 for natural gas, 3 for liquefied petroleum gas, 4 for diesel, 5 for gasoline, 6 for fuel oil, 7 for oil 8 for coke, 9 for kerosene, 10 for import electricity); $t$ is the time period, $t=1,2,3$ (where $t=1$ for 2014 to 2018, 2 for 2019 to 2023, 3 for 2024 to 2028); $P D_{i t}^{ \pm}$is the cost for energy resource $i$ in period $t$ (RMB $¥ /$ ton); $Z_{i t}^{ \pm}$is the supply amount of energy resource $i$ in period $t\left(10^{3}\right.$ ton).

(2) Benefit for local primary energy export:

$E E B^{ \pm}=\sum_{v=1}^{4} \sum_{t=1}^{3} P D X_{v t}^{ \pm} \cdot Z X_{v t}^{ \pm}$

where $v$ is the type of energy source, $v=1,2,3,4$ (where $v=1$ for oil, 2 for diesel, 3 for gasoline); $P D X_{v t}^{ \pm}$is the benefit for export energy resource $v$ in period $t(\mathrm{RMB} ¥ /$ ton $) ; Z X_{v t}^{ \pm}$is the exported amount of energy resource $v$ in period $t\left(10^{3}\right.$ ton).

(3) Cost for power generation:

$P G C^{ \pm}=\sum_{k=1}^{7} \sum_{t=1}^{3} P V_{k t}^{ \pm} \cdot T_{k t}^{ \pm}$

where $k$ is the type of electricity conversion technology, $k=1,2, \ldots$, 7 (where $k=1$ for coal-fired power, 2 for gas-fired power, 3 for diesel-fired power, 4 for wind power, 5 for waste-fired power, 6 for solar power, 7 for cogeneration). $P V_{k t}^{ \pm}$is the fix cost for converting technology $k$ in period $t$ (RMB $¥ 10^{3} / 10^{9} \mathrm{KWh}$ ); $T_{k t}^{ \pm}$is the electricity 
generated by conversion technology $k$ in period $t\left(10^{9} \mathrm{KWh}\right)$.

(4) Cost for capacity of power generation:

$\mathrm{PGCC}^{ \pm}=\sum_{k=1}^{6} \sum_{t=1}^{3} P \mathrm{I}_{k t}^{ \pm} \cdot Y_{k t}^{ \pm} \cdot E_{k t}^{ \pm}$

where $P I_{k t}^{ \pm}$is the variable cost for conversion technology $k$ in period $t\left(\mathrm{RMB} ¥ / 10^{6} \mathrm{KW}\right) ; Y_{k t}^{ \pm}$is the binary variable identifying whether or not capacity expansion option for conversion technology $k$ needs to be undertaken in period $t$; $E_{k t}^{ \pm}$is the capacity expansion option for conversion technology $k$ in period $t\left(10^{3} \mathrm{KW}\right)$.

(5) Cost for heating generation:

$H G C^{ \pm}=\sum_{m=1}^{4} \sum_{t=1}^{3} P R_{m t}^{ \pm} \cdot W_{m t}^{ \pm}$

where $m$ is the type of heating plants technology, $m=1,2,3,4$ (where $m=1$ for coal-fired boiler, 2 for gas-fired boiler, 3 for geothermal heating, 4 for cogeneration); $P R_{m t}^{ \pm}$is the fixed cost for heating technology $m$ in period $t\left(R M B ¥ / \mathrm{m}^{2}\right) ; W_{m t}^{ \pm}$is the heating area for heating technology $m$ in period $t\left(10^{3} \mathrm{~m}^{2}\right)$.

(6) Cost for capacity of heating generation:

$H G C C^{ \pm}=\sum_{m=1}^{4} \sum_{t=1}^{3} P A_{m}^{ \pm} \cdot Y R_{m}^{ \pm} \cdot E R_{m}^{ \pm}$

where $P A_{m t}^{ \pm}$is the variable cost for conversion technology $k$ in period $t\left(\mathrm{RMB} ¥ 10^{3} / 10^{9} \mathrm{KW}\right)$; $Y R_{m t}^{ \pm}$is the binary variable identifying whether or not capacity expansion option $h$ for conversion technology $k$ needs to be undertaken in period $t$; $E R_{m t}^{ \pm}$is the capacity expansion option $h$ for conversion technology $k$ in period $t\left(10^{3} \mathrm{~m}^{2}\right)$.

(7) Cost and variable costs for oil refining:

$O R C^{ \pm}=\sum_{t=1}^{3} P V O_{t}^{ \pm} \cdot R O_{t}^{ \pm}+P P_{t}^{ \pm} \cdot Y Z_{t}^{ \pm} \cdot E Z_{t}^{ \pm}$

where $P V O_{t}^{ \pm}$is the fixed cost for oil refining in period $\mathrm{t}$ (RMB $¥ /$ ton); $R O_{t}^{ \pm}$is the residual capacity for refining technology $\left(10^{3}\right.$ ton/year); $P P_{t}^{ \pm}$is the variable cost for oil refining in period $\mathrm{t}(\mathrm{RMB} ¥ / \mathrm{ton}) ; Y Z_{t}^{ \pm}$ is the binary variable, identifying whether or not capacity expansion option $h$ for oil refining needs to be undertaken in period $t ; E Z_{t}^{ \pm}$ is the capacity expansion option $h$ for oil refining in period $t\left(10^{3}\right.$ ton).

(8) Cost and variable cost for coking:

$C C^{ \pm}=\sum_{t=1}^{3} P W O_{t}^{ \pm} \cdot R W_{t}^{ \pm}+P W_{t}^{ \pm} \cdot Y W_{t}^{ \pm} \cdot E W_{t}^{ \pm}$

where $P W O_{t}^{ \pm}$is the fix cost for oil refining in period $t$ (RMB $¥ /$ ton);
$R W^{ \pm}$is the residual capacity for refining technology ( $10^{3}$ ton/year); $P W_{t}^{ \pm}$is the variable cost for oil refining in period $t$ (RMB $¥ /$ ton); $Y W_{t}^{ \pm}$is the binary variable, identifying whether or not capacity expansion option $\mathrm{h}$ for oil refining needs to be undertaken in period $t ; E W_{t}^{ \pm}$is the capacity expansion option $\mathrm{h}$ for oil refining in period $t$ ( $10^{3}$ ton).

(9) Capital and operation costs for transportation system:

$\mathrm{TSC}^{ \pm}=\sum_{j=1}^{16} \sum_{t=1}^{3} C P_{j t}^{ \pm} \cdot X C_{t}^{ \pm}+\sum_{j=1}^{16} \sum_{t=1}^{3} C R_{j t}^{ \pm} \cdot Y C_{t}^{ \pm} \cdot D_{j t}^{ \pm}$

where $j$ is the type of vehicle $j=1,2, \ldots, 16$ (where $j=1$ for buspetrol, $j=2$ for bus-diesel, $j=3$ for bus-LPG, $j=4$ for taxielectric, $j=5$ for hydrogen, $j=6$ for taxi-petrol, $j=7$ for taxidiesel, $j=8$ for taxi-LPG, $j=9$ for taxi-electric, $j=10$ for taxihydrogen, $j=11$ private car-petrol, $j=12$ private car-diesel, $j=13$ for private car-LPG, $j=14$ for private car-electric, $j=15$ for private car-hydrogen, $j=16$ for subway); $C P_{j t}^{ \pm}$is the purchasing cost for vehicle $j$ in period $t$ (RMB $¥ 10^{3} /$ unit); $X C_{j t}^{ \pm}$is the added amount of vehicle $j$ in period $t$ (unit); $C R_{j t}^{ \pm}$is the consumption fuel amount for vehicle $j$ in period $t\left(10^{3} \operatorname{ton} / 10^{9} \mathrm{~km}\right) ; Y C_{j t}^{ \pm}$is the price of fuel for each type transportation tool (RMB $¥ / \mathrm{L}) ; D_{j t}^{ \pm}$is the trip distance of vehicle $j$ in period $t\left(10^{9} \mathrm{~km}\right)$.

(10) Cost for controlling contamination from electric and heat generation process:

$$
\begin{aligned}
\text { EHCC }^{ \pm}= & \sum_{k=1}^{5} \sum_{l=1}^{4} \sum_{t=1}^{3} P F_{k l t}^{ \pm} \cdot S E R_{k l t} \cdot T_{k t}^{ \pm}+\sum_{m=1}^{3} \sum_{l=1}^{4} \\
& \times \sum_{t=1}^{3} P H_{m l t}^{ \pm} \cdot S E H_{m l t} \cdot W_{m t}^{ \pm}
\end{aligned}
$$

where $l$ is the type of pollutant, $l=1,2,3$ (where $l=1$ for $\mathrm{SO}_{2}, l=2$ for $\mathrm{NO}_{\mathrm{X}}$ and $l=3$ for TSP); $P F_{k l t}^{ \pm}$is the elimination cost of pollutant $l$ for converting technology $k$ in period $t\left(10^{3} \mathrm{RMB} ¥ /\right.$ ton $) ; P H_{m l t}^{ \pm}$is the elimination cost of pollutant $l$ for heating technology in period $t$ (RMB $¥ 10^{3} /$ ton); SER $R_{k t}^{ \pm}$is the generation efficiency for technology $k$ in period $t$ (ton $/ 10^{9 t} \mathrm{KWh}$ ); $S E H_{m}^{ \pm}$is the heating efficiency for technology $m$ in period $t\left(\operatorname{ton} / 10^{3} \mathrm{~m}^{2}\right)$.

\subsection{Constraints}

The constraints define the interrelationships among the decision variables and the waste generation/management conditions. They include:

(1) Constraints of mass balance for coal:

$Z_{1 t}^{ \pm}-Z X_{1 t}^{ \pm} \geq D M C_{t}^{+}-\lambda^{ \pm}\left(D M C_{t}^{+}-D M C_{t}^{-}\right), \forall t$

$Z_{1 t}^{ \pm} \geq C F_{1 t}^{ \pm} \cdot T_{1 t}^{ \pm}+C H_{1 t}^{ \pm} \cdot W_{1 t}^{ \pm}, \forall t$

where $D M C_{t}^{+}$and $D M C_{t}^{-}$are the upper and lower bound of coal demands in period $\mathrm{t}\left(10^{3}\right.$ ton); $C F_{1 t}^{ \pm}$is the coal-fired generation efficiency in period $t$ (ton $\left./ 10^{6} \mathrm{KWh}\right) ; \mathrm{CH}_{1 t}^{ \pm}$is the coal-fired heating 
efficiency in period $t$ (ton $\left./ \mathrm{m}^{2}\right)$.

(2) Constraints of mass balance for natural gas are expressed as follows:

$Z_{2 t}^{ \pm} \geq D M N_{t}^{+}-\lambda^{ \pm}\left(D M N_{t}^{+}-D M N_{t}^{-}\right), \forall t$

$Z_{2 t}^{ \pm} \geq C F_{2 t}^{ \pm} \cdot T_{2 t}^{ \pm}+C H_{2 t}^{ \pm} \cdot W_{2 t}^{ \pm}, \forall t$

where $D M N_{t}^{+}$and $D M N_{t}^{-}$are the upper and lower bound of natural gas demands in period $\mathrm{t}\left(10^{3}\right.$ ton); $C F_{2 t}^{ \pm}$is the gas-fired generation efficiency in period $t\left(\operatorname{ton} / 10^{6} \mathrm{KWh}\right) ; \mathrm{CH}_{2 t}^{ \pm}$is the gas-fired heating efficiency in period $t$ (ton $\left./ \mathrm{m}^{2}\right)$.

(3) Constraints of mass balance for liquefied petroleum gas:

$Z_{3 t}^{ \pm} \geq D M L_{t}^{+}-\lambda^{ \pm}\left(D M L_{t}^{+}-D M L_{t}^{-}\right), \forall t$

$Z_{3 t}^{ \pm} \geq C R_{3 t}^{ \pm} D_{3 t}^{ \pm}+C R_{8 t}^{ \pm} D_{8 t}^{ \pm}+C R_{13 t}^{ \pm} D_{13 t}^{ \pm}, \forall t$

where $D M L_{t}^{+}$and $D M L_{t}^{-}$are the upper and lower bound of liquefied petroleum demand in period $\mathrm{t}\left(10^{3}\right.$ ton).

(4) Constraints of mass balance for diesel are expressed as follows:

$Z_{4 t}^{ \pm}+Z X_{3 t}^{ \pm} \geq D M D_{t}^{+}-\lambda^{ \pm}\left(D M D_{t}^{+}-D M D_{t}^{-}\right), \forall t$

$Z_{4 t}^{ \pm}+Z X_{3 t}^{ \pm} \geq C F_{3 t}^{ \pm} T_{3 t}^{ \pm}+C R_{2 t}^{ \pm} D_{2 t}^{ \pm}+C R_{7 t}^{ \pm} D_{7 t}^{ \pm}+C R_{12 t}^{ \pm} D_{12 t}^{ \pm}, \forall t$

where $D M D_{t}^{+}$and $D M D_{t}^{-}$are the upper and lower bound of diesel demands in period $t$ ( $10^{3}$ ton); $C F_{2 t}^{ \pm}$is the diesel-fired generation efficiency in period $t$ (ton $/ 10^{6} \mathrm{KWh}$ ).

(5) Constraints of mass balance for gasoline are expressed as follows:

$Z_{5 t}^{ \pm}+Z X_{4 t}^{ \pm} \geq D M G_{t}^{+}-\lambda^{ \pm}\left(D M G_{t}^{+}-D M G_{t}^{-}\right), \forall t$

$Z_{5 t}^{ \pm}+Z X_{4 t}^{ \pm} \geq C R_{1 t}^{ \pm} D_{1 t}^{ \pm}+C R_{6 t}^{ \pm} D_{6 t}^{ \pm}+C R_{11 t}^{ \pm} D_{11 t}^{ \pm}, \forall t$

where $D M G_{t}^{+}$and $D M G_{t}^{-}$are the upper and lower bound of gasoline demands in period $t\left(10^{3}\right.$ ton).

(6) Constraints of mass balance for fuel oil are expressed as follows:

$Z_{6 t}^{ \pm} \geq D M F_{t}^{+}-\lambda^{ \pm}\left(D M F_{t}^{+}-D M F_{t}^{-}\right), \forall t$

where $D M F_{t}^{+}$and $D M F_{t}^{-}$are the upper and lower bound of fuel oil demands in period $t\left(10^{3}\right.$ ton).
(7) Constraints of mass for oil refining are expressed as follows:

$$
\begin{aligned}
& Z_{7 t}^{ \pm}+Z X_{2 t}^{ \pm} \geq D M O_{t}^{+}-\lambda\left(D M O_{t}^{+}-D M O_{t}^{-}\right), \forall t \\
& Z_{7 t}^{ \pm}+Z X_{2 t}^{ \pm} \geq \sum_{t=1}^{3}\left(R O_{t}+Y Z_{t}^{ \pm} \cdot E Z_{t}^{ \pm}\right), \quad \forall t
\end{aligned}
$$

where $\mathrm{DMO}_{t}^{+}$and $\mathrm{DMO}_{t}^{-}$are the upper and lower bound of oil demands in period $t\left(10^{3}\right.$ ton).

(8) Constraints of mass for coking refining are expressed as follows:

$Z_{8 t}^{ \pm} \geq D M C K_{t}^{+}-\lambda^{ \pm}\left(D M C K_{t}^{+}-D M C K_{t}^{-}\right), \quad \forall t$

$Z_{8 t}^{ \pm} \geq \sum_{t=1}^{3}\left(R W_{t}+Y W_{t}^{ \pm} \cdot E W_{t}^{ \pm}\right), \quad \forall t$

where $D M C K_{t}^{+}$and $D M C K_{t}^{-}$are the upper and lower bound of coke demands in period $t\left(10^{3}\right.$ ton).

(9) Constraints of mass for kerosene are expressed as follows:

$Z_{9 t}^{ \pm} \geq D M K_{t}^{+}-\lambda^{ \pm}\left(D M K_{t}^{+}-D M K_{t}^{-}\right), \quad \forall t$

where $D M K_{t}^{+}$and $D M K_{t}^{-}$are the upper and lower bound of kerosene demands in period $t\left(10^{3}\right.$ ton).

(10) Constraints of electricity constraints are expressed as follows:

$Z_{10 t}^{ \pm}+\sum_{k=1}^{6} T_{k t}^{ \pm} \geq D M E_{t}^{+}-\lambda^{ \pm}\left(D M E_{t}^{+}-D M E_{t}^{-}\right), \quad \forall t$

$Z_{10 t}^{ \pm}+\sum_{k=1}^{6} T_{k t}^{ \pm} \geq C R_{4 t}^{ \pm} D_{4 t}^{ \pm}+C R_{9 t}^{ \pm} D_{9 t}^{ \pm}+C R_{14 t}^{ \pm} D_{14 t}^{ \pm}, \quad \forall t$

$T_{k t}^{ \pm} \geq F E_{k t}^{ \pm} \cdot\left(R E_{k t}^{ \pm}+Y_{k t}^{ \pm} E_{k t}^{ \pm}\right), \quad \forall t$

where $D M E_{t}^{+}$and $D M E_{t}^{-}$are the upper and lower bound of electricity demands in period $t\left(10^{3}\right.$ ton); $F E_{k t}^{ \pm}$is the operation time for generation technology $k$ in period $t(\mathrm{~h}) ; R E_{k t}^{ \pm}$is the residual capacity for converting technology $k$ (MW).

(11) Constraints of heat constraints are expressed as follows:

$\sum_{m=1}^{3} W_{m t}^{ \pm} \geq D M H_{t}^{+}-\lambda^{ \pm}\left(D M H_{t}^{+}-D M H_{t}^{-}\right), \quad \forall t$ 
$\sum_{m=1}^{3} \sum_{t=1}^{3}\left(R R_{m t}+Y R_{m t}^{ \pm} E R_{m t}^{ \pm}\right) \cdot H_{m}^{ \pm} \geq W_{m}^{ \pm}, \quad \forall t$

where $\mathrm{DMH}_{t}^{+}$and $\mathrm{DMH}_{t}^{-}$are the upper and lower bound of heating demands in period $t\left(10^{3}\right.$ ton); $H_{m t}^{ \pm}$is the capacity utilization rate for heating technology $\mathrm{m}$ in period $t\left(10^{3} \mathrm{~m}^{2} / \mathrm{MW}\right) ; R R_{m t}^{ \pm}$is the residual capacity for converting technology $m$ (MW).

(12) Constraints of transportation constraints are expressed as follows:

$\sum_{j=1}^{16} A P_{j t}^{ \pm} \cdot D_{j t}^{ \pm} \geq T A D_{j t}^{+}-\lambda^{ \pm}\left(T A D_{j t}^{+}-T A D_{j t}^{-}\right), \quad \forall t$

$\left(X C_{j t}^{ \pm}+U C_{j t}^{ \pm}\right) \cdot D P M_{\max t}^{ \pm} \geq D_{j t}^{ \pm}, \quad \forall t$

$\left(X C_{j t}^{ \pm}+U C_{j t}^{ \pm}\right) \cdot D P N_{\text {minjt }}^{ \pm} \geq D_{j t}^{ \pm}, \quad \forall t$

where $T A D_{j t}^{+}$and $T A D_{j t}^{-}$are the upper and lower bound of total amount of traffic demand for vehicle $j$ in period $t$ ( $10^{9}$ personkilometers); $A P_{j t}^{ \pm}$is the average busload for vehicle $j$ in period $t$ (person/unit); $U C_{j t}^{ \pm}$is the amount of vehicle $\mathrm{j}$ in base year; $D P M_{j t}^{ \pm}$is the maximum trip distance for per vehicle $\mathrm{j}$ using in period $\mathrm{t}$ $\left(10^{9} \mathrm{~km}\right) ; D P N_{i 5}^{ \pm}$is the minimum trip distance for per vehicle $\mathrm{j}$ using in period $\mathrm{t}\left(10^{9} \mathrm{~km}\right)$.

(13) Constraints of environmental constraints are expressed as follows:

$$
\begin{aligned}
& \sum_{k=1}^{7} \sum_{l=1}^{4} \sum_{t=1}^{3}\left(1-\eta_{l}\right) \cdot T_{k t}^{ \pm} S E R_{k t}^{ \pm}+\sum_{m=1}^{4} \sum_{l=1}^{4}\left(1-\eta_{l}\right) \cdot W_{m t}^{ \pm} S E H_{m k t}^{ \pm} \\
& \quad \leq \sum_{t=1}^{3} S E_{l t}^{+}-\lambda^{ \pm}\left(S E_{l t}^{+}-S E_{l t}^{-}\right), \forall t
\end{aligned}
$$

$\sum_{j=1}^{16} \sum_{o=1}^{3} \sum_{t=1}^{3} D_{j t}^{ \pm} \cdot T D_{j o t}^{ \pm} \leq \sum_{o=1}^{3} \sum_{t=1}^{3} S E T_{o t}^{+}-\lambda^{ \pm}\left(S E T_{o t}^{+}-S E T_{o t}^{+}\right), \forall t$

where $o$ is the type of pollutant, $o=1,2,3$ (where $o=1$ for HC, $o=2$ for $\mathrm{NO}_{\mathrm{X}}$ and $o=3$ for $\mathrm{CO}$ ); $\eta_{l}$ is the average emission rate of pollutant $l$ in period $t(\%) ; S E_{l t}^{+}$and $S E_{l t}^{-}$are the upper and lower bounds of the allowable emission level for pollutant $l$ in period $t$ (ton); $S E T_{o t}^{+}$and $S E T_{o t}^{-}$are upper and lower bounds of allowable emission level for pollutant $o$ from transportation system in period $t$ (ton); $T D_{j o t}^{ \pm}$is the average emission rate of pollutant $o$ for vehicle $j$ in period $t$ (ton/ $\left.10^{9} \mathrm{~km}\right)$.

(14) Constraints for capacity expansion:

$Y_{k t}^{ \pm}\left\{\begin{array}{ll}=1, & \text { if capacity expansion of is undertaken } \\ =0, & \text { if otherwise }\end{array} \forall k, t\right.$
$Y R_{m t}^{ \pm}\left\{\begin{array}{lll}=1, & \text { if capacity expansion of is undertaken } \\ =0, & \text { if otherwise }\end{array} \forall m, t\right.$

$Y Z_{t}^{ \pm}\left\{\begin{array}{ll}=1, & \text { if capacity expansion of is undertaken } \\ =0, & \text { if otherwise }\end{array} \forall t\right.$

$Y_{t}^{ \pm}\left\{\begin{array}{l}=1, \quad \text { if capacity expansion of is undertaken } \\ =0, \quad \text { if otherwise }\end{array} \forall t\right.$

(15) Constraints of technical constraints are expressed as follows:

$Z_{i t}^{ \pm} \geq 0, \forall i, t$

$Z X_{v t}^{ \pm} \geq 0, \forall v, t$

$T_{k t}^{ \pm}, E_{k t}^{ \pm} \geq 0, \forall k, t$

$W_{m t}^{ \pm}, E R_{m t}^{ \pm} \geq 0, \forall m, t$

$E Z_{t}^{ \pm}, E W_{t}^{ \pm} \geq 0, \forall t$

$X C_{j t}^{ \pm}, D_{j t}^{ \pm} \geq 0, \forall j, t$

\section{Results and discussion}

Solutions obtained through IF-MEM are presented in Figs. 4-12. Most of the results for the objective function value and most of the non-zero decision variables are interval numbers. Generally, solutions presented as intervals demonstrated that the related decisions should be sensitive to the uncertain modeling inputs. The results of IF-MEM may shed light on the advantages of the government's decision and even potentially cause adjustment of local policy.

\subsection{Energy allocation}

Energy resources used in the city can be divided into nine types, such as import coal, natural gas, liquefied petroleum gas, diesel, gasoline, fuel oil, coke, kerosene and import electricity. Fig. 4 presents the results of energy resources supply. Obviously, coal was the largest source during the planning periods. But coal would show a decline trend due to the environment protection and sustainable development. For example, the supply of coal would gradually decrease from $[354.4,401.7] \times 10^{6}$ ton in period 1 to [320.3, 354.2] $\times 10^{6}$ ton in period 3 . This trend is due to the facts that demands for electricity would increase over the planning horizon and the price of coal is relatively cheaper than the other resources (e.g., natural gas, and oil). Since the local coal supply could not meet the domestic increasing demand, the city has to import coal from other regions such as Shanxi, Inner-Mongolia and Hebei provinces. The supply of coke would show a sharply increase trend from period 1 to period 2 (i.e., [48.0, 49.5] $\times 10^{6}$ ton in period 1 and [71.4, $82.4] \times 10^{6}$ ton in period 2 ) due to high speedy industry 


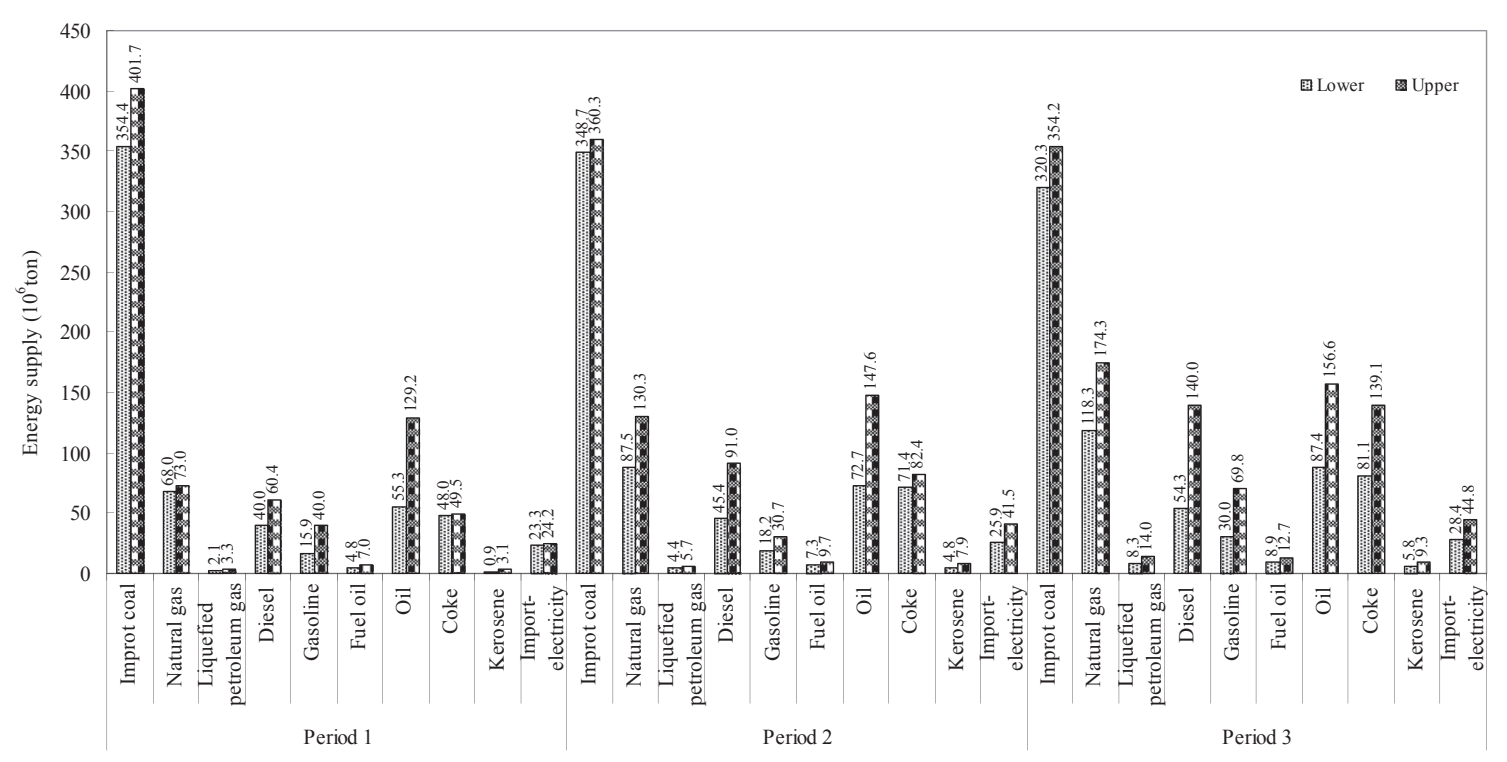

Fig. 4. Solutions of energy supply.

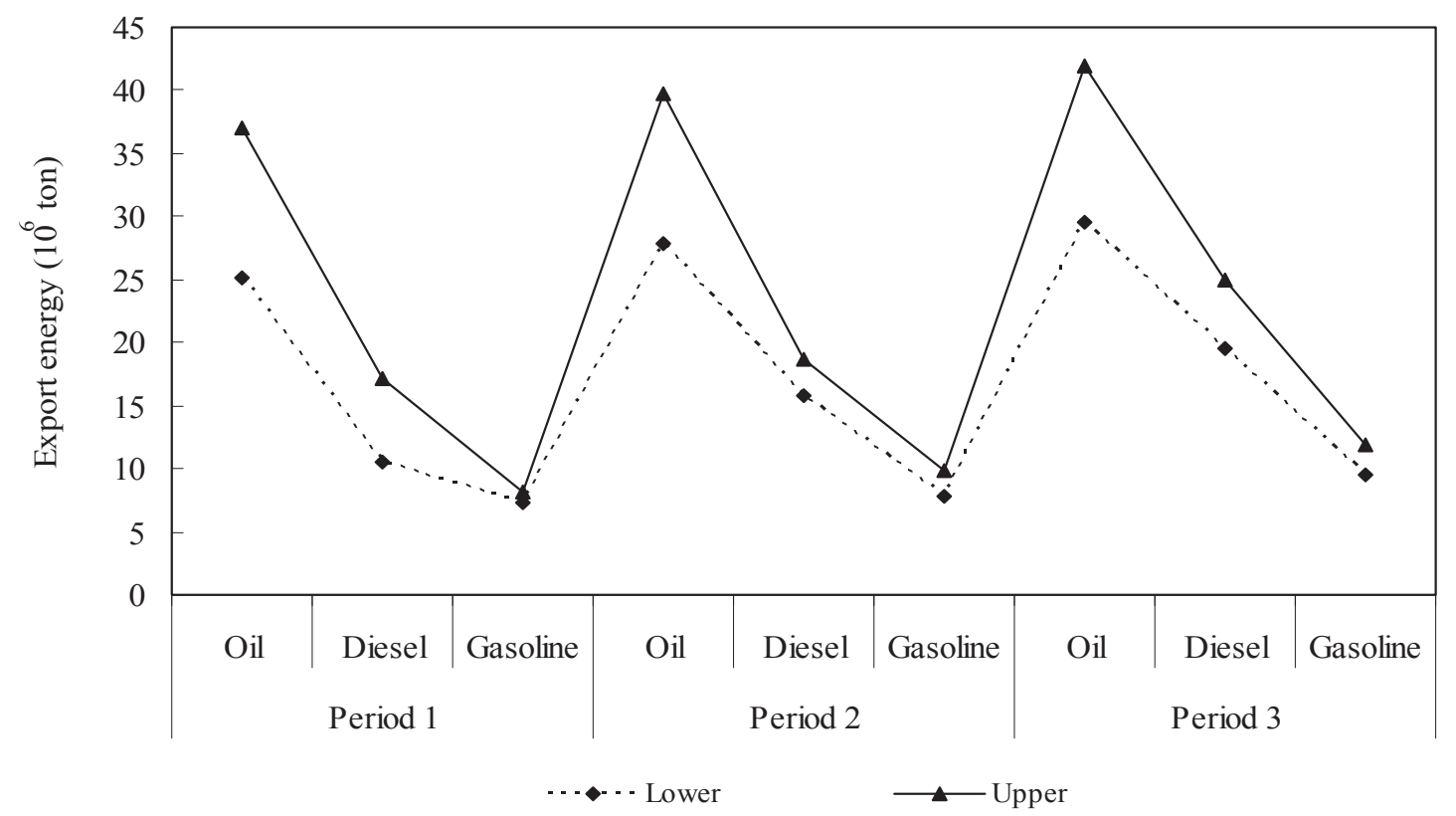

Fig. 5. Solutions of energy export.

development, because of Tianjin developed industrial (e.g., iron and steel industry, petrochemical industry and metallurgical industry). Considering environment protection, some relatively clean energy resources would be vigorously encouraged over the planning horizon. For example, natural gas would become the one of the most competitive resources, which would increase from [67.9, $72.9] \times 10^{9} \mathrm{~m}^{3}$ in period 1 to $[118.3,174.3] \times 10^{9} \mathrm{~m}^{3}$ in period 3 , with a growth rate of $[74.19,137.72] \%$. The local gas supply capacity cannot meet the city's demand for natural gas, leading to that the city has to depend on the "West-to-East Gas Transport" project to import the nature gas. In addition, liquefied petroleum gas (LPG) is one of clean energy resources, which would grow up 4 times over the planning horizon.

The total supply of crude oil would also increase over the planning horizon $\left([55.3,129.2] \times 10^{6}\right.$ ton in period $1,[72.7$, $147.6] \times 10^{6}$ ton in period 2 , and $[87.4,156.6] \times 10^{6}$ ton in period 3 ).
The city is a main crude oil exporter in the northern China; a massive amount of crude oil is transported to the other regions (e.g., Hebei province and Beijing). The crude oil exported would gradually increase from $[25.2,36.9] \times 10^{6}$ ton to $[29.5,41.9] \times 10^{6}$ ton (As shown in Fig. 5). Gasoline and diesel are consumed mostly by passenger vehicles and electricity generation. As the dramatic increase of transport tool, the total supplies of gasoline and diesel have an obviously increased trend. Noteworthy, gasoline with a growth rate of about $12 \%$, which mainly due to its dominant role for running vehicles.

Fig. 5 presents the results of export energy for the city. The amount of gasoline exported would increase from $[7.3,8.1] \times 10^{6}$ ton in period 1 to $[9.5,11.9] \times 10^{6}$ ton in period 3 ; the amount of diesel exported would increase from $[10.6,17.1] \times 10^{6}$ ton in period 1 to $[19.5,24.9] \times 10^{6}$ ton in period 3 . Consequently, some innovative technologies should be developed to use alternative fuels 


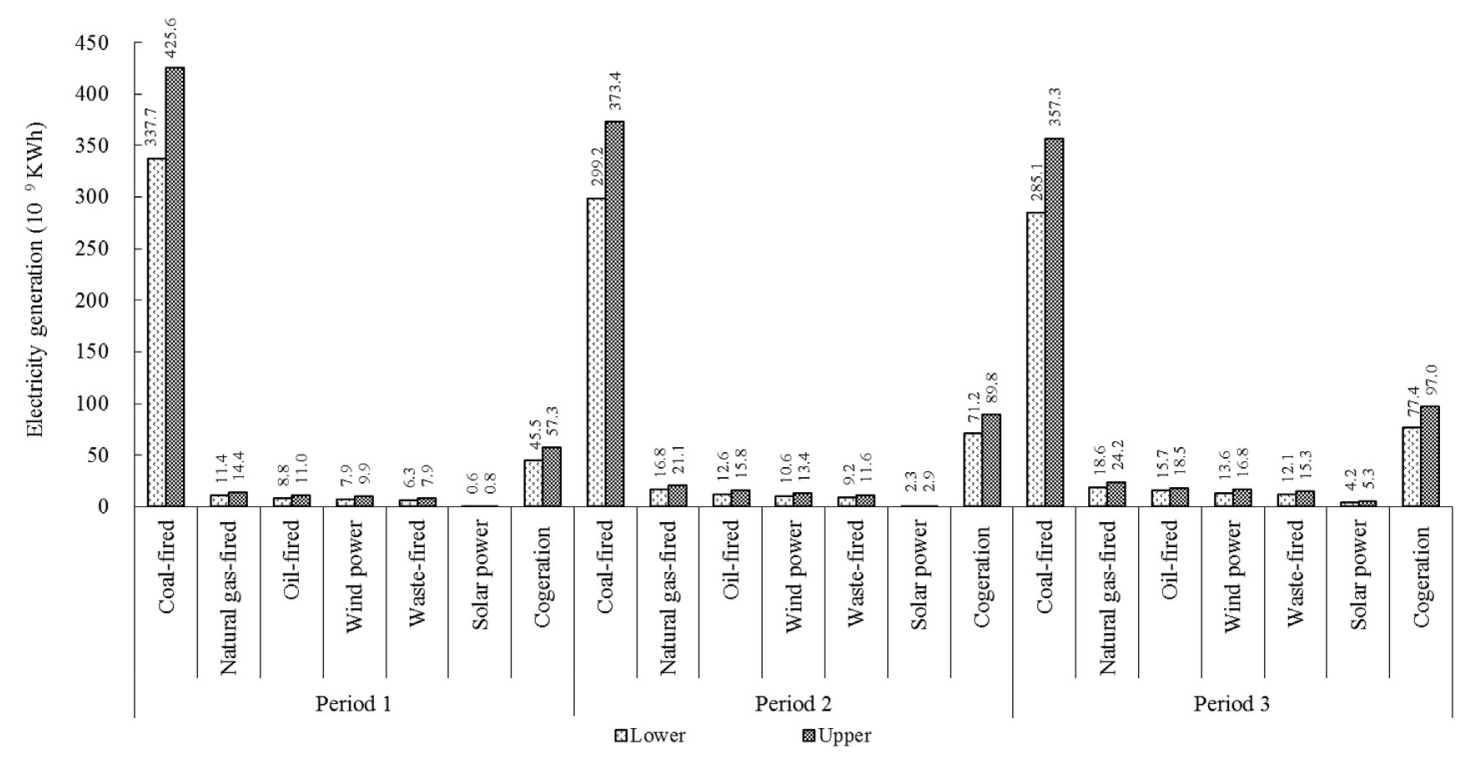

Fig. 6. Electricity generation pattern.

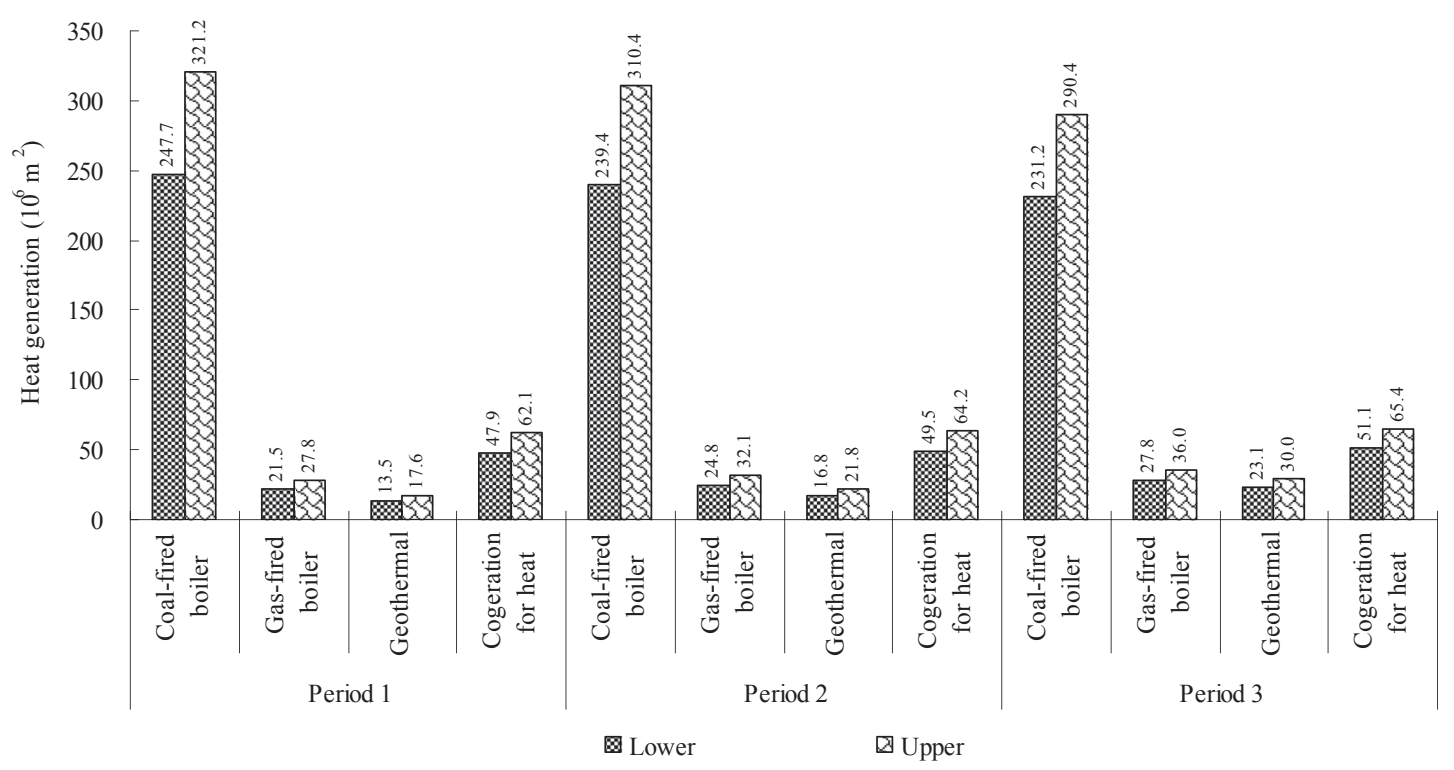

Fig. 7. Heat generation of conversion technology type in heat power plant.

(e.g., LPG, hydrogen, natural gas and electricity) to mitigate the environmental pollution issues. In general, the amount of each energy supply would rise up because of increasing energy demand over the planning horizon; clean energy would be the major sources in the future for Tianjin. For the city, optimizing the conventional energy structure (i.e. utilizing non-fossil fuels to replace fossil fuels), improving the energy supply and utilization efficiencies, and increasing energy infrastructure investment are desired. When electricity generated from local power plant cannot meet the end-users demand, electricity supply shortage would occur. Imported electricity is one of the effective actions. The results indicate that imported electricity would increase from [23.3, $24.2] \times 10^{9} \mathrm{KWh}$ in period 1 to $[28.4,44.8] \times 10^{9} \mathrm{KWh}$ in period 3 , which occupied about [15.8, 19.2]\% of the total electricity consumption in period 1 and $[22.9,28.9] \%$ of it in period 3, respectively.

\subsection{Electricity generation}

Fig. 6 shows the solutions of electricity-generation pattern (i.e., coal-fired power, gas-fired power, diesel-fired power, wind power, waste-fired power, solar power and cogeneration). The total amount of electricity generation would rise to meet the increasing end-user demands, being [418.1, 526.9] $\times 10^{9} \mathrm{KWh},[421.9$, $528.0] \times 10^{9} \mathrm{KWh}$, and $[426.7,534.4] \times 10^{9} \mathrm{KWh}$ in periods 1 to 3 , respectively. Coal-fired power holds the dominant position for electricity generation over the planning horizon. However, the amount of coal-fired power would decrease from $81 \%$ in period $1-66 \%$ in period 3, mainly because of serious atmosphere pollution and the city's energy development strategies. In comparison, natural gas and oil would be the most competitive forms of power generation over the planning horizon, and the amounts of them have shown sharply increased trend. Besides, cogeneration as an 


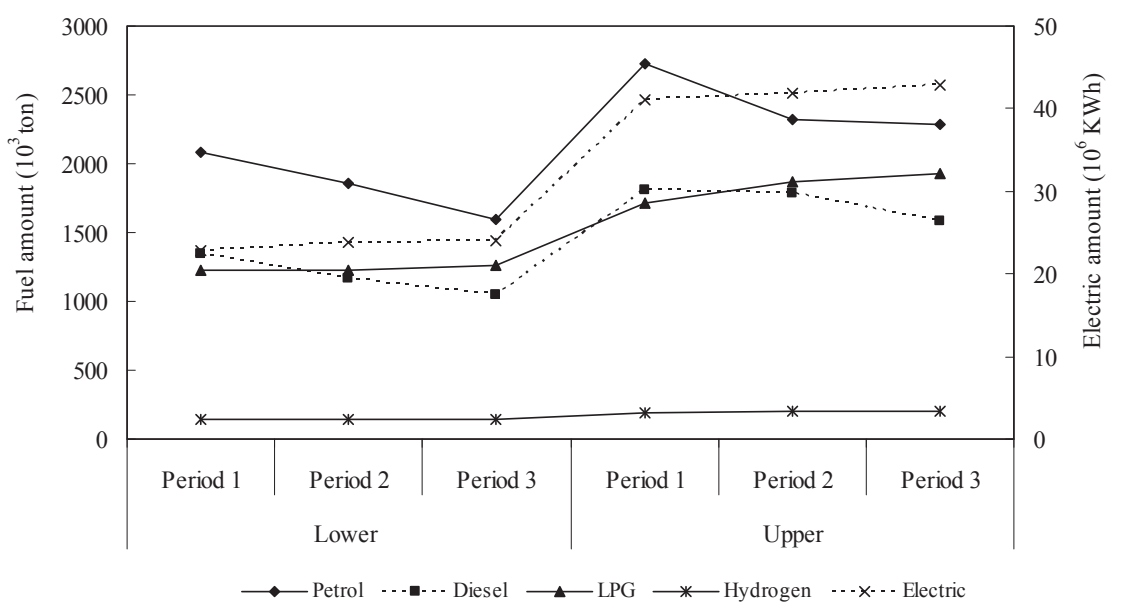

Fig. 8. Consumption fuels from traffic system.
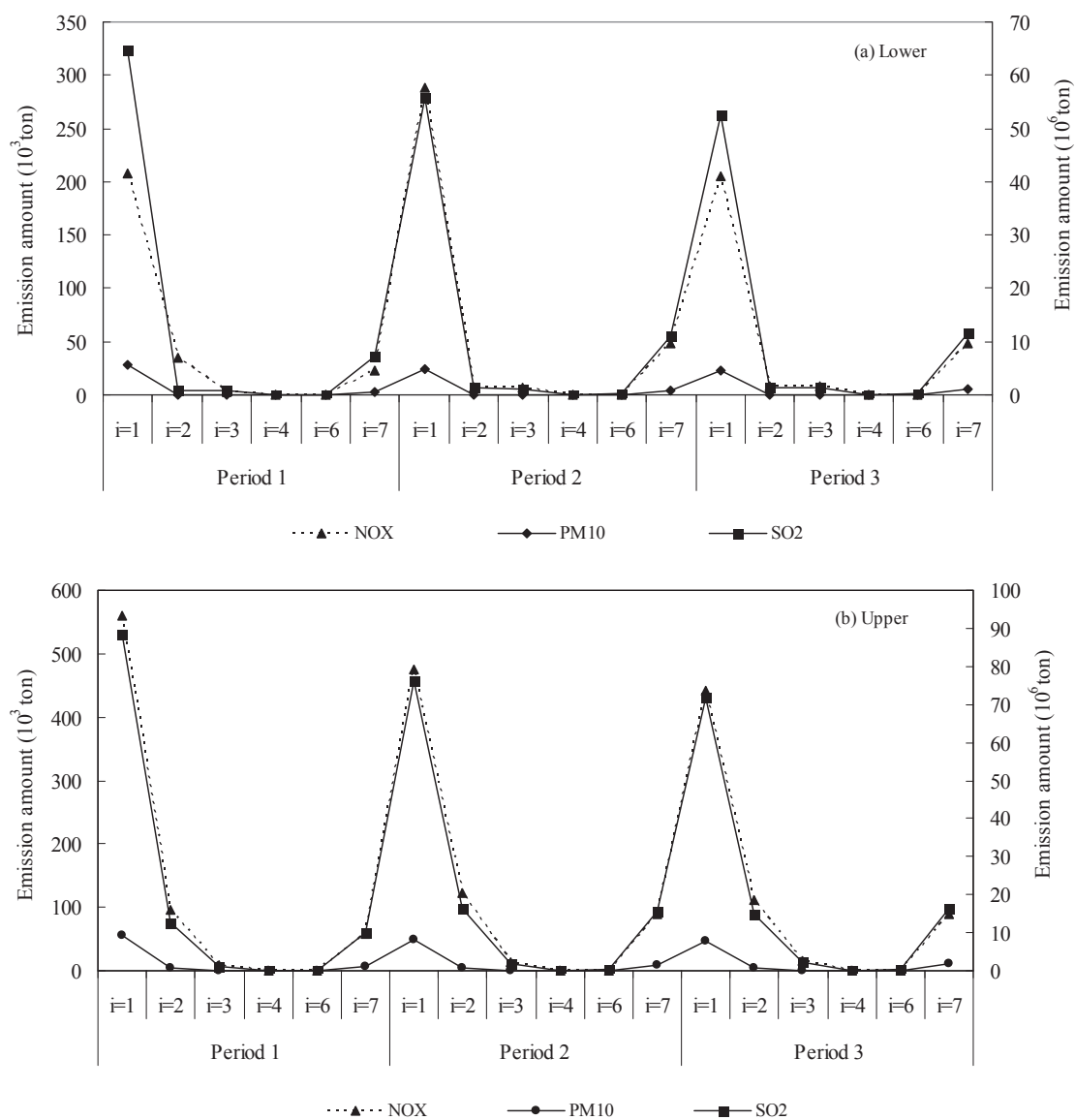

Fig. 9. Solutions of pollutant emission from the electric power system.

advanced technology could supply electricity and heat at the same time, which is beneficial to environment protection. The proportion of cogeneration would obviously increase during periods 1 to 3 (i.e., i.e., $[45.5,57.3] \times 10^{9} \mathrm{KWh}$ in period $1,[71.2,89.8] \times 10^{9} \mathrm{KWh}$ in period 2 and $[77.4,97.0] \times 10^{9} \mathrm{KWh}$ in period 3$)$. In addition, renewable energy power conversion technologies would be vigorously encouraged in the future. The wind power, waste-fired power and solar power are shown substantial rise trend. The amount of wind power would increase from $[7.9,9.9] \times 10^{9} \mathrm{KWh}$ in period 1 to
$[13.6,16.8] \times 10^{9} \mathrm{KWh}$ in period 3 , which has an increase rate of $[69.69,72.15] \%$. In general, coal-fired power generation would be restricted and its proportion would gradually decrease over the planning horizon. While, some relatively clean power (i.e., natural gas-fired power, oil-fired power) and renewable energy power conversion technologies (i.e., wind power, waste-fired power and solar power) would be vigorously encouraged with considering pollutant mitigation requirement. Although electricity demand is showing a sharply increase trend, renewable energy generation 

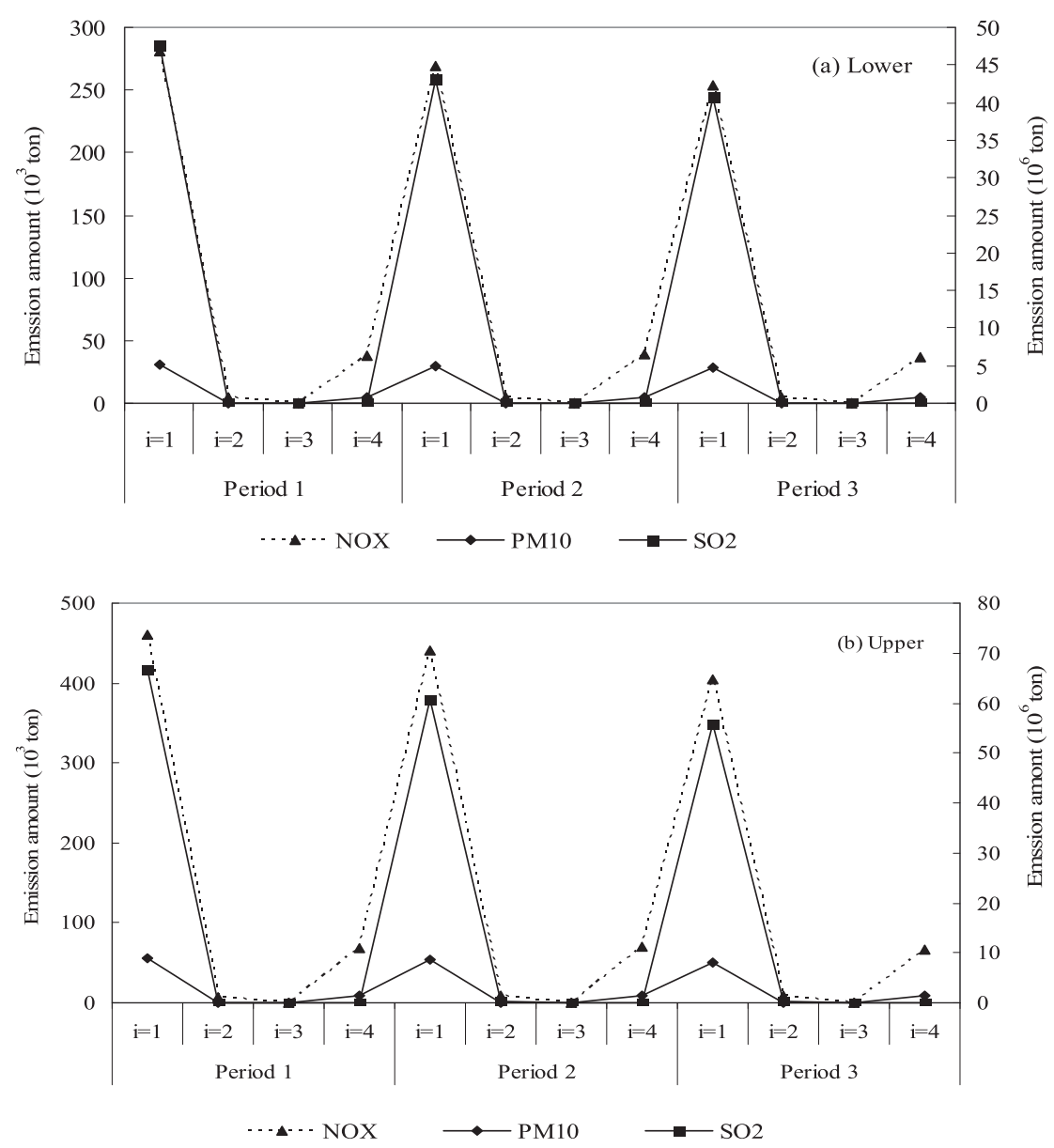

Fig. 10. Solutions of pollutant emission from heat generation system.

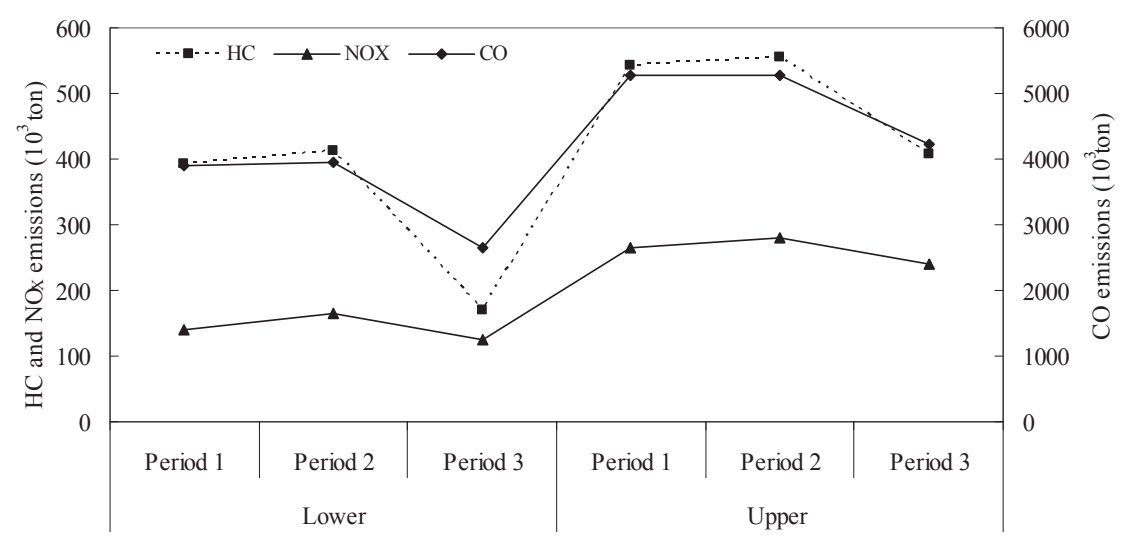

Fig. 11. Solutions pollutant emission from the traffic system.

would undertake enormous development space. It is requisite to promote the utilization of renewable energy resources. As important measures to guarantee Tianjin's energy security, the development and utilization of renewable energy are crucial for supporting pollutant emission reduction and solving energy shortage crisis.

\subsection{Heat generation}

Fig. 7 shows the heat generation pattern in thermal power plants. Results indicate that the coal-fired heating plants would gradually decreased in periods 1 to 3 (with a reducing rate of [6.6, $9.6] \%)$. On the contrary, gas-fired heating plants would increase from $[21.5,27.8] \times 10^{6} \mathrm{~m}^{2}$ in period 1 to $[27.8,36.0] \times 10^{6} \mathrm{~m}^{2}$ in period 3(with a growth rate of 29.5\%). The heating area from geothermal resources would reach to $[13.5,17.6] \times 10^{6} \mathrm{~m}^{2}$ in period $1,[16.8,21.8] \times 10^{6} \mathrm{~m}^{2}$ in period 2 , and $[23.1,30.0] \times 10^{6} \mathrm{~m}^{2}$ in period 3. Heat supplied from cogeneration heating plants would gradually increase from $[47.9,62.1] \times 10^{6} \mathrm{~m}^{2}$ in period $1,[49.5$, $64.2] \times 10^{6} \mathrm{~m}^{2}$ in period 2 and $[51.1,65.4] \times 10^{6} \mathrm{~m}^{2}$ in period 3 , respectively. Generally, for the city, the coal-fired technology would 


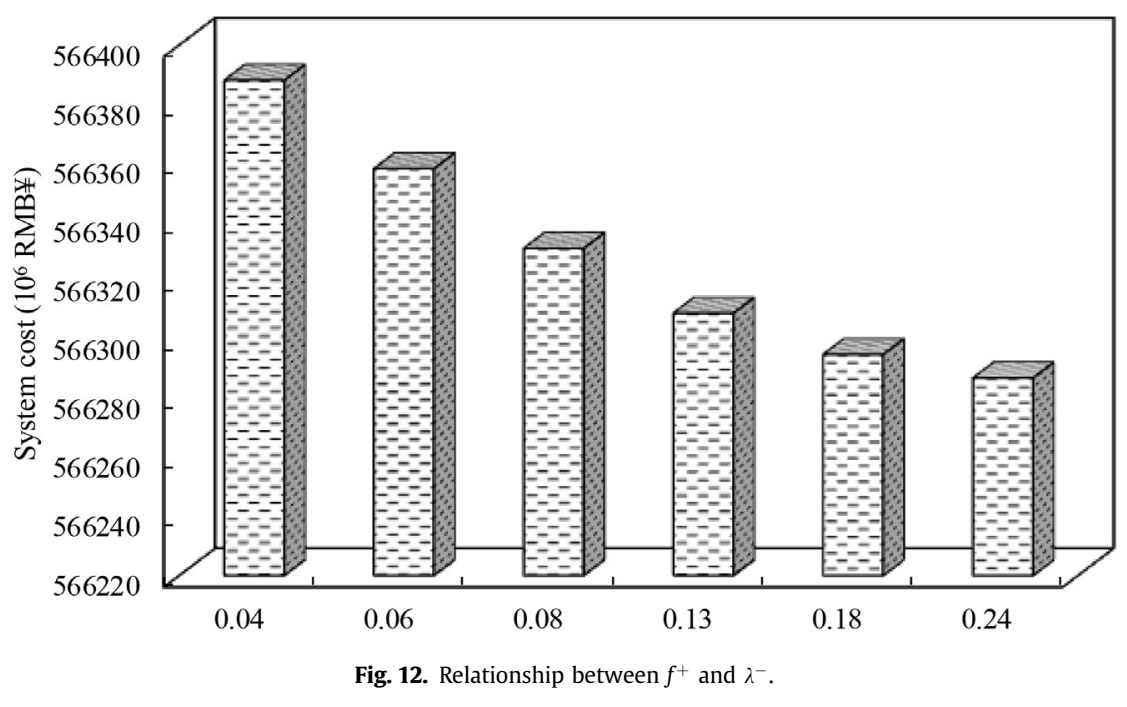

still be the dominant one although its proportion declined in the future.

\subsection{Energy consumption from traffic system}

Fig. 8 presents the energy consumption for the city's traffic system. Results indicate that the amount of traditional fossil fuels (i.e., gasoline, diesel) would decrease over the planning horizon. For example, the amount of gasoline consumption from traffic systems would decrease from [2081.6, 2721.8] $\times 10^{3}$ ton in period 1 to $[1589.8,2289.4] \times 10^{3}$ ton in period 3. While, clean energy (i.e., LPG and hydrogen) would show an obviously increase trend over the planning horizon. Take LGP for example, it would increase from $[1222.4,1715.2] \times 10^{3}$ ton in period 1 , to $[1262.5,1928.2] \times 10^{3}$ ton in period 3. In addition, the electric motive vehicles would be encouraged because of it is beneficial to environment protection and sustainable development. The electricity amount from traffic consumption would increase from $[22.9,41.1] \times 10^{6} \mathrm{KWh}$ in period 1 to $[24.0,42.8] \times 10^{6} \mathrm{KWh}$ in period 3 . In conclusion, the amount of gasoline and diesel consumption from traffic systems would decrease $[16,24] \%$ and $[12,23] \%$, respectively; and the amount of clean energy resources (i.e., LPG, electric and hydrogen) would increase $[15,23]$ \% during the planning periods. The results indicate traditional fossil fuels are still major fuel (i.e., gasoline and diesel) for traffic system. But it would be limited to development over the planning periods; while, some comparatively clean energy (i.e., LPG, hydrogen and electric) would be vigorously encouraged, which mainly attribute to the continuously shrinking fossil fuel reserves and requirement for environment protection.

\subsection{Environmental management}

Pollutant emissions are associated with energy-related activities. Figs. 9 and 10 present the results of pollutant emissions from electricity and heat generation, respectively. The results indicate the coal-fired technology (i.e., coal-fired power and heat) would be the major contributor for atmosphere pollution. For example, in period 1 , the coal-fired technology would produce $[78.6,87.7] \%$ $\left(\mathrm{SO}_{2}\right), 77.6 \%\left(\mathrm{NO}_{\mathrm{x}}\right)$ and $[84.0,88.3] \%\left(\mathrm{PM}_{10}\right)$ of the total emissions generated by the city's energy system. While, due to the environment protection and sustainable development requirements, the proportion of coal-fired capacities would be reduced, and some renewable and clean power and heat technologies would be increased to meet the increasing demands. Therefore, the pollutant emissions would be accordingly decreased over the planning horizon. For example, the emission amounts of $\mathrm{SO}_{2}, \mathrm{NO}_{\mathrm{X}}$ and $\mathrm{PM}_{10}$ would reduce $[10.01,11.19] \%$ (from $[121.5,179.4] \times 10^{6}$ ton in period 1 to $[107.9,161.3] \times 10^{6}$ ton in period 3 ), $[4.74,9.64] \%$ (from [591.9, $1258.8] \times 10^{6}$ ton in period 1 to $[563.8,1137.4] \times 10^{6}$ ton in period 3 , and $[8.64,8.74] \%$ (from $[67.5,133.0] \times 10^{3}$ ton in period 1 to $[61.6$, $121.5] \times 10^{3}$ ton in period 3 ), respectively.

Fig. 11 shows the typical pollutant emissions from traffic system. $\mathrm{CO}, \mathrm{HC}$ and $\mathrm{NO}_{\mathrm{x}}$ emissions are the principal sources of traffic system. The results indicate that the traffic system would be one of major pollutant emission sources. Take period 2 for example, the $\mathrm{NO}_{\mathrm{x}}$ generated from traffic system account for $[18.7,19.9] \%$ of the total $\mathrm{NO}_{\mathrm{x}}$ emissions in the city. As Fig. 10 shows, the emissions (i.e., $\mathrm{CO}, \mathrm{HC}$ and $\mathrm{NO}_{\mathrm{x}}$ ) would slender increase from period 1 to period 2 , while, decrease during period 2 to period 3. For example, CO emissions would be $[3910.9,5269.3] \times 10^{3}$ ton in period 1 , [3945.0, $5271.0] \times 10^{3}$ ton in period 2 , and $[2660.3,4226.8] \times 10^{3}$ ton in period 3 , respectively. The amount of $\mathrm{HC}$ emissions would be $[392.8,543.2] \times 10^{3}$ ton in period $1,[412.5,553.9] \times 10^{3}$ ton in period 2 , and $[269.9,407.0] \times 10^{3}$ ton in period 3 , respectively. And the amount $\mathrm{NO}_{\mathrm{x}}$ emissions would $[140.56,265.7] \times 10^{3}$ ton in period $1,[164.7,280.2] \times 10^{3}$ ton in period 2 , and [125.2, $240.2] \times 10^{3}$ ton in period 3 , respectively. This is mainly attributes two aspect: (i) the sharply increasing demand for traffic tools; (ii) the development of new energy-saving and environmentalfriendly vehicle. It implies that the development of renewable energy would effectively improve the environmental quality. Consequently, the city would better to speeding up the utilization of renewable energy.

\subsection{System cost}

The IF-EME is to achieve a maximized satisfaction degree for system objective and constraints under uncertainty. The expected system cost is RMB $¥[485,788,566,372] \times 10^{6}$, with the degree of satisfaction $\left(\lambda_{\text {opt }}^{ \pm}\right)$being $[0.032,0.922]$. The lower system cost value represents as an alternative with a lower energy demand-level, whereas the higher one corresponds to an alternative with a higher energy demand-level. As a result, planning with a higher system cost would guarantee that the energy requirements and environmental regulations are met; in comparison, as the plan aims towards a lower system cost, these requirements may not be met. The $\lambda^{ \pm}$level corresponds to the decision maker's preference regarding reliability and economic tradeoffs. A $\lambda^{ \pm}$level close to " 1 " 
would correspond to a high possibility of satisfying the constraints/ objective under advantageous conditions; conversely, a $\lambda^{ \pm}$value near " 0 " would be related to a solution that has a low possibility of satisfying the constraints/objective under demanding conditions. Fig. 12 presents the relationship between $f^{+}$and $\lambda^{-}$, where the solution of $\lambda^{-}$denotes the degree of satisfying the system objective/ constraints under uncertainty. The $\lambda^{-}=0.04$ corresponds to a higher united system cost (RMB $¥ 566,388 \times 10^{6}$ ), representing a minimum degree of satisfaction under demanding conditions. A raised $\lambda^{-}$level would lead to a decreased system cost over the planning horizon (i.e., the system cost would be RMB¥ $566,295 \times 10^{6}$ when $\lambda^{-}=0.13$, and RMB $¥ 566,287 \times 10^{6}$ when $\left.\lambda^{-}=0.24\right)$. Therefore, decisions with a lower constraint-violation risk would be associated with a higher system cost but increased system reliability; a desire for a lower system cost would result in a raised risk of violating the system constraints.

\section{Conclusions}

In this study, an interval-fuzzy municipal-scale energy model (IF-MEM) has been developed, which integrates interval-parameter programming (IPP) and fuzzy programming (FP) into an integer programming framework for planning energy systems of Tianjin. In IF-MEM, parameter uncertainties expressed as discrete intervals and fuzzy sets can be effectively tackled. Solutions with different satisfaction degree levels concerning energy resources allocation, electricity generation, heat generation, expansion schemes, energy consumption of traffic systems evaluation, and emission reduced policy have been generated. Results can help decision makers identify desired policies under various system costs and constraintviolation risks, as well as allow in-depth analyses tradeoffs among economic objective, satisfaction degree and constraint-violation risk. In IF-MEM, decisions with a lower constraint-violation risk would be associated with a higher system cost but increased system reliability; a desire for a lower system cost would result in a raised risk of violating the system constraints.

The developed model is applied to Tianjin's energy systems under a variety of uncertainties. Several finding can be revealed as follows: (i) the city's energy structure tends to transition from coaldominated into diversity energy structure. Coal's consumption would decrease $[10,12] \%$. While, natural gas would become the one of the most competitive resources, which with a growth rate of [74.2, 139.1]\%; liquefied petroleum gas (LPG) would grow up 4 times over the planning horizon; (ii) coal-fired holds the dominant position, but its proportion would reduce from $81 \%$ in period 1 to $66 \%$ in period 3; (iii) traditional fossil fuels for traffic system would be limited and comparatively clean energy would be encouraged, gasoline and diesel consumptions from traffic system would decrease $[16,24] \%$ and $[12,23] \%$, respectively; the comparatively clean energy resources (i.e., LPG, electric and hydrogen) would increase $[15,23] \%$ during the planning periods, which would contribute about $[20,32] \%[20,31] \%$, and $10 \%$ reductions in CO, HC and NOX emissions; (iv) SO2, NOx and PM10 emissions from electricity and heat generations would reduce [10.1, 11.2]\%, [4.7, $9.6] \%$ and $[8.6,8.7] \%$ during the planning periods, because of the restriction of fossil fuels and the development of clean and renewable energy technologies. Although this study is the first attempt for Tianjin's energy system management through the developed IF-MEM, the model results suggest that this method is applicable of providing decisions for energy system management.

\section{Acknowledgments}

This research was supported by the National Natural Science Foundation for Distinguished Young Scholar (51225904), the
National High-tech R\&D (863) Program (2012AA091103), and the National Postdoctoral Science Foundation (2015M570140). The authors are grateful to the editors and the anonymous reviewers for their insightful comments and suggestions.

\section{References}

[1] L.M. Pekala, R.R. Tan, D.C.Y. Foo, J.M. Jezowski, Optimal energy planning models with carbon footprint constraints, Appl. Energy 86 (6) (2010) 1903-1910.

[2] Key world energy statistics. OECD/IEA (2011).

[3] China Statistic Bureau. China energy supply and consumption (2011).

[4] Y. Zhu, Y.P. Li, G.H. Huang, Planning carbon emission trading for Beijing's electric power systems under dual uncertainties, Renew. Sustain. Energy Rev. 23 (2013) 113-128.

[5] Z. Kravanja, L. Cucek, Multi-objective optimisation for generating sustainable solutions considering total effects on the environment, Appl. Energy 101 (2013) 67-80.

[6] Y.P. Cai, G.H. Huang, Z.F. Yang, Q. Tan, Identification of optimal strategies for energy management systems planning under multiple uncertainties, Appl. Energy 86 (2009) 480-495.

[7] A.F.A. Khella, Egypt: energy planning policies with environmental considerations, Energy Policy 25 (1) (1997) 105-115.

[8] C. Cormio, M. Dicorato, A. Minoia, M. Trovato, A regional energy planning methodology including renewable energy sources and environmental constraints, Renew. Sustain. Energy Rev. 7 (2) (2003) 99-130.

[9] M.I. Howells, T. Alfstad, D.G. Victor, G. Goldstein, U. Remme, A model of household energy services in a low-income rural African village, Energy Policy 33 (14) (2005) 1833-1851.

[10] D. Henning, S. Amiri, K. Holmgren, Modelling and optimisation of electricity, steam and district heating production for a local Swedish utility, Eur. J. Operational Res. 175 (2) (2006) 1224-1247.

[11] T. Unger, T. Ekvall, Benefits from increased cooperation and energy trade under $\mathrm{CO}_{2}$ commitments - the Nordic case, Clim. Policy 3 (3) (2003) 279-294.

[12] M. Toksari, Estimating the net electricity energy generation and demand using the ant colony optimization approach: case of Turkey, Energy Policy 37 (3) (2009) 1181-1187.

[13] Y.F. Li, G.H. Huang, Y.P. Li, Y. Xu, W.T. Chen, Regional-scale electric power systems planning under uncertainty-a multistage interval-stochastic integer linear programming approach, Energy Policy 38 (1) (2010) 475-490.

[14] H. Ren, W. Gao, A MILP model for integrated plan and evaluation of distributed energy system, Appl. Energy 87 (3) (2010) 1001-1004.

[15] L.D.S. Coelho, A.A.P. Santos, A BRF neural network model with GARCH errors: application to electricity price forecasting, Electr. Power Syst. Res. 8 (1) (2011) 74-83.

[16] C. Chen, Y.P. Li, G.H. Huang, An inexact robust optimization method for supporting carbon dioxide, Energy Econ. 40 (2013) 441-456.

[17] M.Z. Chen, G.Q. Chen, B. Chen, Embodied carbon dioxide emission by the globalized economy: a systems ecological input-output simulation, J. Environ. Inf. 21 (1) (2013) 35-44.

[18] V. Vahidinasab, Optimal distributed energy resources planning in a competitive electricity market: multiobjective optimization and probabilistic design, Renew. Energy 66 (2014) 354-363.

[19] H. Borhanazad, S. Mekhilef, V.G. Ganapathy, M. Modiri-Delshad, A. Mirtaheri, Optimization of micro-grid system using MOPSO, Renew. Energy 71 (2014) 295-306.

[20] Q. Hu, G.H. Huang, Y.P. Cai, W. Sun, Planning of electric power generation systems under multiple uncertainties and constraint-violation levels, J. Environ. Inf. 23 (1) (2014) 55-64.

[21] K. Huang, L.M. Dai, W.W. Huang, Effects of operation time of pavement and traffic flow on the traffic noise of the highways in an urban area, J. Environ. Inf. 24 (2) (2014) 121-130.

[22] S. Sanaye, A. Sarrafi, Optimization of combined cooling, heating and power generation by a solar system, Renew. Energy 80 (2015) 699-712.

[23] L.G. Fishnone, H.M. Abilock, MARKAL, a linear programming model for energy systems analysis: technical description of the BNL version, Int. J. Energy Res. 5 (1981) 353-375.

[24] H. Turtona, L. Barreto, Long-term security of energy supply and climate change, Energy Policy 34 (5) (2006) 2232-2250.

[25] C.O. Wene, B. Ryden, A comprehensive energy model in the municipal energy planning process, Eur. J. Operational Res. 33 (2) (1988) 212-222.

[26] D. Finon, Un modele energetique pour la France, Centre Nationale de la Recherche Scienti-fique, Paris, 1976, p. 39.

[27] D. Yeung, J.M. Hartwick, Interest rate and output price uncertainty and industry equilibrium for non-renewable resource extracting firms, Resour. Energy 10 (1985) $1-14$

[28] P.E. Grohnheit, B.O.G. Mortensen, Competition in the market for space heating: district heating as the infrastructure for competition among fuels and technologies, Energy Policy 31 (9) (2003) 817-826.

[29] E. Muela, G. Schweickardt, F. Garces, Fuzzy possibilistic model for mediumterm power generation planning with environmental criteria, Energy Policy 35 (2007) 5643-5655. 
[30] Y. Zhu, Y.P. Li, G.H. Huang, Planning municipal-scale energy systems under functional interval uncertainties, Renew. Energy 39 (2012) 71-84.

[31] C. Chen, Y.P. Li, G.H. Huang, Y. Zhu, An inexact robust nonlinear optimization method for energy systems planning under uncertainty, Renew. Energy 47 (2012) 55-66.

[32] A. Khosrvi, S. Nahavandi, D. Creighton, Quantifying uncertainties of neural network-based electricity price forecasts, Appl. Energy 112 (2013) 120-129.

[33] M.Q. Suo, Y.P. Li, G.H. Huang, D.L. Deng, Y.F. Li, Electric power system planning under uncertainty using inexact inventory nonlinear programming method, J. Environ. Inf. 22 (1) (2013) 49-67.

[34] N.B. Chang, Y.L. Chen, S.F. Wang, A fuzzy interval multiobjective mixed integer programming approach for the optimal planning of solid waste management systems, Fuzzy Sets Syst. 89 (1) (1997) 35-59.

[35] G.H. Huang, N. Sae-Lim, L. Liu, Z. Chen, An interval-parameter fuzzy-strochastic programming approach for municipal solid waste management and planning, Environ. Model. Assess. 6 (2001) 271-283.

[36] D.Y. Miao, W.W. Huang, Y.P. Li, Z.F. Yang, Planning water resources systems under uncertainty using an interval-fuzzy De Novo programming method J. Environ. Inf. 24 (1) (2014) 11-23.

[37] Y.P. Li, G.H. Huang, Interval-parameter two-stage stochastic nonlinear programming for water resources management under uncertainty, Water Resour. Manag. 22 (6) (2008) 681-698.

[38] Y. Zhu, G.H. Huang, Y.P. Li, L. He, X.X. Zhang, An interval full-infinite mixedinteger programming method for planning municipal energy systems - a case study of Beijing, Appl. Energy 88 (2011) 2662-2846.

[39] D. Dubios, H. Prade, On fuzzy interpolation, Int. J. General Syst. 28 (2) (1999) $103-112$.

[40] H.J. Zimmermann, Applications of fuzzy sets theory to mathematical programming, Inf. Sci. 36 (1985) 29-58.

[41] G.H. Huang, B.W. Baetz, G.G. Patry, Grey integer programming: an application to waste management planning under uncertainty, Eur. J. Operational Res. 83 (1995) 594-620.

[42] Tianjin Statistical Yearbook 2010.

[43] Tianjin Statistical Yearbook 2012

[44] The Chinese Energy Statistical Yearbook.

[45] Q.J. Dou, Research on the Control Countermeasures of Urban Traffic Congestion Problems in Tianjin, Tianjin University of Commerce, 2012.

[46] According to Chinese Environment Statistical Yearbook (2013).

[47] C. Dong, G.H. Huang, Y.P. Cai, Y. Liu, An inexact optimization modeling approach for supporting energy systems planning and air pollution mitigation in Beijing city, Energy 37 (1) (2012) 673-688.

[48] J. Herp, U.V. Poulsen, M. Greiner, Wind farm power optimization including flow variability, Renew. Energy 81 (2015) 173-181.

[49] Y.P. Li, G.H. Huang, X. Chen, An interval-valued minimax-regret analysis approach for the identification of optimal greenhouse-gas abatement strategies under uncertainty, Energy Policy 39 (7) (2011) 4313-4324.

[50] Tianjin Statistical Yearbook 2005-2009. 